\title{
E1 PRINCIPIO DE COMPLEMENTARIEDAD Y LAS ESTRATEGIAS DE ACTUACIÓN DE LA CORTE PENAL INTERNACIONAL EN LA FASE DE EXAMEN PRELIMINAR:
}

\author{
Prof. dr. Héctor Olásolo Alonso \\ Fecha de recepción: 28 de julio de 2012 \\ Fecha de evaluación:3 de agosto de 2012 \\ Fecha de aprobación: 3 de agosto de 2012
}

\section{Resumen}

El presente artículo analiza el papel relevante que en la actualidad desempeña la Corte penal Internacional luego de diez años de vigencia en constante evolución, frente a las situaciones que requieran la activación de la competencia de la justicia penal internacional. En concreto el texto analiza el cuestionamiento que surge sobre por qué la CPI mantiene el examen preliminar en relación con los asuntos de Colombia y porqué no abre una investigación con respecto a la situación nacional.

\section{Abstract}

This article analyzes the role that currently plays the International Criminal Court after ten years in constant evolution, with situations that require the activation of the jurisdiction of international criminal justice. In particular the text analyzes the question that arises on why the ICC maintains the preliminary examination in relation to the Affairs of Colombia and why not open an investigation with respect to the national situation.

\section{Palabras clave:}

Principio de complementariedad, admisibilidad de casos, examen preliminar, para política, jurisdicción de justicia y paz

\section{Key words:}

Principle of complementarity, admissibility of cases, preliminary examination, for policy, jurisdiction of Justice and peace

\footnotetext{
- Magister en Derecho por Universidad de Columbia (Nueva York), licenciado y premio extraordinario de doctorado por la Universidad de Salamanca (España); Presidente del Instituto Ibero-Americano de la Haya para la Paz, los Derechos Humanos y la Justicia Internacional (IIH); catedrático de derecho internacional público y derecho internacional penal y procesal, y director del área de justicia internacional de la Universidad Santo Tomás de Aquino (USTA) en Bogotá (Colombia); co-director de la clínica jurídica sobre derecho internacional humanitario de la Universidad del Rosario en Bogotá (Colombia); Profesor Visitante en la Universidad de las Ciencias Aplicadas de la Haya. El autor ha sido también letrado de Sala de la Corte Penal Internacional (2004-2010), miembro de la asesoría jurídica y de la sección de apelaciones del Tribunal Penal Internacional para la ex Yugoslavia (2002-2004); miembro de la delegación espanola en la Comisión Preparatoria para la Corte Penal Internacional celebrada en la sede de la Organización de las Naciones Unidas en Nueva York (1999-2002); y catedrático de Derecho penal y procesal internacional de la Universidad de Utrecht (febrero 2009septiembre 2012). El autor ha escrito una docena de monografías y más de cincuenta artículos en revistas de reconocido prestigio en español e inglés.
} 


\section{Introducción: Relevancia de la CPI en el marco de la Comunidad Internacional y principio de complementariedad}

Coincidiendo con el décimo aniversario de la Corte Penal Internacional ("CPI"), ésta se enfrenta a uno de los momento más críticos de su historia, al haber sido arrestados en Libia el 7 de junio de 2012 varios de los integrantes de una delegación de la oficina de apoyo a la defensa enviada para informar a Saif Al-Islam Gaddafi (quien desde el año pasado permanece detenido por las autoridades del Consejo Revolucionario de Libia) sobre sus derechos en el proceso actualmente abierto contra el mismo ante la $\mathrm{CPI}^{1}$.

Este incidente pone de manifiesto la relevancia asumida en los últimos diez años por la CPI en el marco de la Comunidad Internacional como consecuencia de las más de 9.000 comunicaciones recibidas hasta el día de hoy, los exámenes preliminares sobre las situaciones de crisis en Afganistán, Colombia, Corea del Sur, Georgia, Guinea, Honduras, Irak, Nigeria, Palestina y Venezuela, y las investigaciones sobre las situaciones en Costa de Marfil, Darfur (Sudán), Kenia, Libia República Centro-Africana, República Democrática del Congo, y Uganda ${ }^{2}$ - a lo que hay que añadir situaciones como la relativa a la violencia sistemática y a gran escala desatada desde el año 2006 en México a raíz de la llamada "guerra contra los cárteles del narcotráfico", que se encuentra en un estadio previo al examen preliminar propiamente dicho tras la comunicación recibida por la Fiscalía el 25 de noviembre de $2011^{3}$.

Si se da un rápido repaso a los numerosos conflictos armados y situaciones de violencia sistemática o a gran escala que se han desarrollado en los últimos diez años en el mundo, la relevancia de la función de la CPI no era sino una cuestión de tiempo, teniendo en cuenta su mandato y fin último de terminar con la impunidad de los máximos responsables de aquellos delitos que más gravemente afectan a la Comunidad Internacional como el genocidio, los delitos de lesa humanidad y los crímenes de guerra

Sin embargo, nadie podía esperar en 2002, que la CPI se convirtiera en pocos años en un actor relevante en un número tan importante de situaciones ocurridas a lo largo y ancho de la geografía africana, latino-americana y asiática. De hecho, todavía se pueden recordar aquellos tiempos no muy lejanos cuando en 2004, la Fiscalía de la CPI tenía dificultades iniciar su primera investigación, centrándose finalmente en los delitos cometidos en Ituri, una provincia periférica de la República Democrática del Congo con una población de menos de cuatro millones de personas.

La relevancia del papel asumido por la CPI en el marco de la Comunidad Internacional en sus diez primeros años de existencia, y las numerosas situaciones en las que actúa de manera directa o indirecta, hace que la propia CPI, y en particular su Fiscalía, haya tenido que diseñar un plan de acción con respecto a cada una de ellas dependiendo de sus principales características y de los fines últimos del mandato de la CPI: De ahí que en $2003^{4}, 2006^{5}$ y $2007^{6}$ la Fiscalía haya presentado tres documentos relativos a distintos aspectos de su política criminal, además del documento que sobre exámenes preliminares apareció en $2010^{7}$.

\footnotetext{
1 Véase, http://www.icc-cpi.int/NR/exeres/64EFE7B7-5951-4102-BF03-B1C758EB1AD0.htm

${ }^{2}$ Véase, http://www.icc-

cpi.int/Menus/ICC/Structure + of + the + Court/Office + of + the + Prosecutor/Comm + and + Ref/Communications + and + Referrals.ht $\underline{\mathrm{m}}$.

3Véase,http://ww.bbc.co.uk/mundo/ultimas noticias/2011/11/111125 ultnot mexico solicitud corte penal_internacional_i nvestigacion calderon irg.shtml .

${ }^{4}$ Fiscalía de la CPI, Paper on some policy issues before the Office of the Prosecutor, 1-9, ICC-OTP 2003 (Sept. 2003), disponible en www.icc-cpi.int/NR/rdonlyres/1FA7C4C6-DE5F-42B7-8B25-60AA962ED8B6/143594/030905 Policy Paper.pdf

${ }_{5}^{5}$ Fiscalía de la CPI, Report on Prosecutorial Strategy, 1-11 (Sept. 14, 2006), disponible en http://www.icccpi.int/NR/rdonlyres/D673DD8C-D427-4547-BC69-2D363E07274B/143708/ProsecutorialStrategy20060914 English.pdf. "Fiscalía de la CPI, Policy Paper on the Interests of Justice, 1-9, ICC-OTP 2007 (Sept. 2007), disponible en bttp://wmw.icccpi.int/NR/rdonlyres/772C95C9-F54D-4321-BF09-73422BB23528/143640/ICCOTPInterestsOfJustice.pdf

${ }^{7}$ Fiscalía de la CPI, "Borrador de Políticas sobre Exámenes Preliminares", 4 de octubre de 2010, disponible en: http://www.icc-cpi.int/NR/rdonlyres/E278F5A2-A4F9-F3D7-38D26A2C9CF5D7D7/282515/OTP Draftpolicypaperonpreliminaryexaminations04101.pdf.
} 
Una vez que la Fiscalía de la CPI se dio cuenta de la dimensión de las funciones que le habían sido encomendadas ( $\mathrm{y}$ en particular de la relevancia del examen preliminar de las distintas situaciones de crisis a los efectos de terminar la procedencia de iniciar una investigación sobre los delitos cometidos en las mismas), preparó en mayo de 2010 un documento sobre los "exámenes preliminares" en el que se afirma que para distinguir aquellas situaciones en las que se justifica la apertura de una investigación de aquéllas otras que esta medida no se justifica, la Fiscalía ha establecido un proceso de filtro que incluye la siguientes cuatro fases:

(a) La Fase 1 proporciona una valoración inicial de toda la información recibida sobre presuntos delitos conforme al artículo 15 (“comunicaciones"), a los efectos de filtrar toda la información relativa a delitos que se encuentran manifiestamente fuera de la jurisdicción de la Corte;

(b) La Fase 2, que representa el inicio formal del examen preliminar, consiste en un análisis de toda la información sobre presuntos delitos, incluyendo las "comunicaciones" que no fueron rechazadas durante la Fase 1, la información relativa a las remisiones de un Estado Parte o del Consejo de Seguridad, las declaraciones realizadas conforme al artículo 12 (3), información de fuentes públicas, así como declaraciones recibidas en la sede de la Corte;

a. En la Fase 2(a), el análisis se centra en cuestiones relativas a la jurisdicción personal, temporal o territorial de la Corte;

b. En la Fase 2(b) el análisis tiene por objeto los presuntos delitos dentro de la jurisdicción material da Corte.

(c) La Fase 3 se centra en el análisis de admisibilidad;

(d) La Fase 4 examina la cuestión de los intereses de la justicia para de esta manera poder realizar una recomendación final sobre la existencia de una base razonable para iniciar una investigación ${ }^{8}$.

De estas cuatro fases, la tercera conlleva un análisis de admisibilidad mediante la aplicación de los criterios recogidos en el art. 17 del ER con independencia de que la situación de se trate haya sido remitida a instancia del Consejo de Seguridad de las Naciones Unidas, de un Estado Parte, o por cualquier otra persona jurídica o natural a través de una comunicación'. Pero además, si tenemos en cuenta que el art. 53 (1) y (2) ER requieren un análisis exclusivamente negativo de los llamados "intereses de la justicia" (de manera que la apertura de una investigación no requiere la misma sirva para promover los intereses de la justicia, sino que es suficiente con que no se haya identificado ningún factor en particular que recomiende no entrar a investigar una situación en un determinado momento $)^{10}$, se puede afirmar que, una vez afirmada la sistematicidad o gran escala de la conducta punible, el análisis requerido en la fase de examen preliminar se va a centrar en si se dan las condiciones necesarias para que la CPI ejercite su jurisdicción teniendo en cuenta su carácter complementario.

En este sentido, el principio de complementariedad (que no de subsidiaridad como algunos autores lo han descrito), desarrollado por los arts.1, 17, 18, 19 y $20 \mathrm{ER}$, tiene como fundamento un sistema de soberanía compartida entre la CPI y las jurisdicciones nacionales ${ }^{11}$. Conforme a este principio, la CPI constituye una jurisdicción de última ratio que solo puede activarse y ejercitarse ante la inacción, la falta de disposición o la falta de capacidad de las jurisdicciones nacionales ${ }^{12}$. De ahí que

\footnotetext{
8 Ibid, párr. 86.

9 Ibid, párrafos 51-72. En 2011, el Fiscal anunció la apertura de una investigación sobre la base de la remision por parte del Consejo de Seguridad de la ONU de la "situación" en Libia desde el 15 de febrero de 2011, tras concluir que "tras un examen preliminar de la información disponible [...] una investigación está justificada”. Véase el comunicado de prensa de la Fiscalía de la CPI, "El Fiscal de la CPI abrirá una investigación en Libia“, 2 de marzo de 2011.

${ }^{10} \mathrm{H}$. Olásolo Alonso, "Admisibilidad de situaciones y casos objeto de procesos de procesos de justicia de transición ante la Corte Penal Internacional”, en H. Olásolo Alonso, Ensayos sobre Derecho Penal y Procesal Internacional, Tirant lo Blanch \& Instituto Ibero.-Americano de la Haya (IIH), Valencia, 2011 (reimpreso en 2012 en Medellín, Colombia, por la editorial Dike, la Unión Europea y el Ministerio de la Justicia y el Derecho de Colombia), p. 86 [en adelante: Olásolo Alonso, Admisibilidad de situaciones y casos]

${ }^{11}$ H. Olásolo Alonso, "De los Riesgos y las Precauciones necesarias en la Aplicación del Principio de Complementariedad por la Corte Penal Internacional: El Estudio de la Determinación de las Penas como Objeto de Análisis de Admisibilidad", en H. Olásolo Alonso, Ensayos de Derecho Penal y Procesal Internacional, Tirant lo Blanch \& Instituto Ibero.-Americano de la Haya (IIH), Valencia, 2011 (reimpreso en 2012 en Medellín, Colombia, por la editorial Dike, la Unión Europea y el Ministerio de la Justicia y el Derecho de Colombia), p. 128.

12 Ibid, p. 119.
} 
pueda afirmarse la primacía formal de las jurisdicciones nacionales sobre la CPI, con la que se pretende promover a nivel nacional las investigaciones y los enjuiciamientos de los "crímenes más graves de trascendencia para la Comunidad Internacional en su conjunto" con pleno respeto a los principios de justicia recogidos en el Estatuto de Roma ("ER")

Ahora bien, al mismo tiempo, se pueda observar también como el principio de complementariedad incluye un segundo aspecto consistente en la primacía material de CPI, puesto que es esta última la que tiene la última palabra sobre si, a la luz de las actuaciones de las jurisdicciones nacionales, una situación es admisible ante la CPI. La primacía material de la CPI se dirige a terminar con la impunidad en aquellos supuestos en los que haya conseguido impedir la investigación y enjuiciamiento por las jurisdicciones nacionales de los presuntos responsables de los delitos previstos en el Estatuto de Roma ${ }^{14}$.

De esta manera, conforme al artículo 17 (1) ER, la CPI podrá ejercitar su jurisdicción sólo si (i) las autoridades nacionales están inactivas, tienen falta de disposición o tienen falta de capacidad, y (ii) la situación o caso de que se trate caso es lo suficientemente grave ${ }^{15}$. La primera parte de este análisis se refiere a las investigaciones y enjuiciamientos desarrollados por las jurisdicciones nacionales. Así, en el art. 17(1)(a) a (c) del ER, se establece que la CPI no podrá ejercer su jurisdicción por problemas de admisibilidad porque la situación de que se trate: (i) esté siendo realmente investigado o enjuiciado por un estado que tiene competencia sobre el mismo, (ii) haya sido realmente investigado por un estado que tiene competencia sobre el mismo y tal estado ha decidido no enjuiciar a la persona de que se trate; o (iii) la persona de que se trata ya ha sido realmente enjuiciada por la conducta a la que se refiere la denuncia y un juicio en la Corte violaría el principio un bis in idem ${ }^{16}$. En estos supuestos, sólo si se puede verificar la existencia de un problema de falta de disposición o de falta de capacidad de las jurisdicciones nacionales de los estados afectados cabrá declarar la situación admisible y proceder a la apertura de la investigación ${ }^{17}$.

Según el art. 17(2) ER, nos encontramos ante un supuesto de falta de disposición de las jurisdicciones nacionales aun en el caso de que estén o hayan investigado y/o enjuiciado, cuando, a la luz de los principios de un proceso con todas las garantías reconocidas por el derecho internacional, se puede afirmar que las actuaciones nacionales: (a) se llevan a cabo con el "propósito de sustraer al acusado de su responsabilidad penal por crímenes de la competencia de la Corte"; (b) sufren una demora injustificada que es incompatible con la intención de hacer comparecer a la persona de que se trate ante la justicia; o (c) no son sustanciadas de manera independiente o imparcial, y además no resultan compatibles con la intención de hacer comparecer a la persona de que se trate ante la justicia $^{18}$.

Por su parte, el artículo 17 (3) ER define los supuestos de falta de capacidad como aquéllos en los que las jurisdicciones nacionales afectadas, debido "al colapso total o sustancial de su administración de justicia o al hecho de carecer de la misma", no pueden hacer comparecer al acusado, no disponen de las pruebas o de los testimonios necesarios, o no se encuentran en

\footnotetext{
13 Olásolo Alonso, Admisibilidad de situaciones y casos (supra n. 10), pp. 60-61.

14 Ibid, p. 61.

15 Idem.

16 Ibid, pp. 61-62.

17 Idem.

18 S.A. Williams, "Article 17. Issues of Admissibility", en O. Triffterer (coord.) Commentary on the Rome Statute of the International Criminal Court, pp. 383-394, p. 394; y T. Holmes, "The Principle of Complementarity”, en R.S. Lee (coord.) The International Criminal Court. The Making of the Rome Statute, Kluwer International Law, 1999, pp. 41-78, pp. 54-55. Lógicamente, en los casos del art. 17 (1)(c) ER en los que las jurisdicciones nacionales han dictado sentencia firme, no cabe ya hablar de una demora injustificada en el desarrollo de unas actuaciones nacionales que ya han concluido. Por eso, en estos casos, el art. 20 (3) ER se refiere únicamente a que las actuaciones nacionales se hayan llevado a cabo con el "propósito de sustraer al acusado de su responsabilidad penal por crímenes de la competencia de la Corte"; o (b) no hayan sido sustanciadas de manera independiente o imparcial, ni sean compatibles con la intención de hacer comparecer a la persona de que se trate ante la justicia. En opinión del autor, este mismo tratamiento se debería haber dado a los supuestos del art. 17(1)(b) ER que se caracterizan porque las autoridades nacionales han concluido su investigación y han decidido no ejercitar la acción penal. De otra manera, una vez que se toma la decisión de no incoar la acción penal, las actuaciones nacionales adolecerán necesariamente de una "demora injustificada" puesto que dicha decisión provocará el archivo de las actuaciones. Véase a este respecto, H. Oráoslo, Corte Penal Internacional: ¿Dónde Investigar?, Tirant lo Blanch/Cruz Roja Española, Valencia, 2003, pp. 219-221
} 
condiciones de llevar a cabo el juicio oral. Se trata, en definitiva, de supuestos excepcionales que pueden tener lugar, por ejemplo, en un contexto de ausencia de un gobierno central, de una guerra civil o de un desastre natural que provoque un colapso total o sustancial en la administración de justicia $^{19}$.

Finalmente, la segunda parte del análisis de admisibilidad se refiere a la "gravedad" del asunto. El art. 17(1)(d) del ER estipula que una situación es inadmisible cuando no es de gravedad suficiente para justificar la adopción de otras medidas por la $\mathrm{CPI}^{20}$, lo que según las decisiones de autorización para la apertura de la investigación en las situaciones de Kenia y Costa de Marfil, requiere la aplicación de criterios como el numero de víctimas, el tipo de delito, manera de cometerlo o su impacto en las comunidades afectadas ${ }^{21}$.

\section{Aplicación del principio de complementariedad a través del análisis de admisibilidad de casos: consideraciones para afirmar la admisibilidad de los casos ante la CPI contra Germain Katanga, Joseph Kony y Jean Pierre-Bemba.}

El análisis de admisibilidad se realiza en dos momentos distintos. En primer lugar, en la fase de examen preliminar a los efectos de decidir si ha de iniciarse o no una investigación sobre una determinada situación de crisis ("análisis de la admisibilidad de una situación") 22. Posteriormente, cuando una vez abierta la investigación, y a resultas de la misma, se dicta una orden de arresto o de comparecencia contra una persona por su presunta intervención en la comisión de ciertos delitos ("análisis de admisibilidad de un caso") 23.

La jurisprudencia de la CPI desarrolló primero los análisis de admisibilidad de casos, afirmando que en los mismos se analiza, además de la gravedad de la conducta imputada al sospechoso, las actuaciones de los órganos jurisdiccionales nacionales con respecto a la posible responsabilidad penal del sospechoso en los delitos que se le imputan ante la CPI, a los efectos de determinar la acción o la inacción de las autoridades nacionales al respecto y, en caso de que se hayan desarrollado actuaciones judiciales a nivel nacional, analizar si las mismas no sufren de una falta de disposición o de capacidad ${ }^{24}$.

Sólo con posterioridad, la CPI definió el análisis de admisibilidad de situaciones durante la fase de examen preliminar, afirmando que dicho análisis debe realizarse con respecto a los casos potenciales, definidos por categorías de personas y tipos de delitos, que centrarán la investigación de la Fiscalía de la CPI en caso de que se abra la misma ${ }^{25}$. De esta manera, la CPI analiza que actuaciones judiciales se han desarrollado sobre el grupo de casos potenciales de la situación de crisis bajo examen preliminar, a los efectos de determinar la acción o inacción de las autoridades nacionales, y, en su caso, la posible falta de voluntad o capacidad de las mismas ${ }^{26}$.

En lo que se refiere a su aplicación práctica, los primeros análisis de admisibilidad fueron realizados con respecto a casos de Uganda, República Democrática del Congo y República Centro-

\footnotetext{
19 Olásolo Alonso, Admisibilidad de situaciones y casos (supra n. 10), p. 62.

20 H. Olásolo Alonso \& E. Carnero Rojo, "Aplicación práctica del análisis de admisibilidad de situaciones: la situación en la República de Kenia”, en H. Olásolo Alonso, Ensayos de Derecho Penal y Procesal Internacional, Tirant lo Blanch \& Instituto Ibero.Americano de la Haya (IIH), Valencia, 2011 (reimpreso en 2012 en Medellín, Colombia, por la editorial Dike, la Unión Europea y el Ministerio de la Justicia y el Derecho de Colombia), p. 98 [en adelante: Olásolo Alonso \& Carnero Rojo, Admisibilidad de la situación en Kenia]

21 Situación in the Republic of Kenya, Pre-Trial Chamber II, Decision Pursuant to Article 15 of the Rome Statute on the Authorization of an Investigation into the Situación in the Republic of Kenya, ICC-01/09-19, 31 de marzo de 2010, párr.. 60-62 y 188. Véase también, Situación in Cote d'Ivorie, Decision Pursuant to Article 15 of the Rome Statute on the Authorization of an Investigation into the Situtation in the Republic of Cote d'Ivorie, 3 de octubre de 2011.

22 Olásolo Alonso \& Carnero Rojo, Admisibilidad de la situación en Kenia (supra n. 20), pp. 94 a 97.

23 Idem.

24 Idem.

25 Ibid, pp. 107-110.

26 Idem.
} 
Africana. Así, en el caso contra Joseph Kony y varios de los comandantes de más alto rango en el Ejército de Liberación del Señor (grupo armado de oposición que se enfrenta las fuerzas gubernamentales ugandesas desde el año 1985), la Sala de Cuestiones Preliminares II concluyó que el Acuerdo sobre Responsabilidad y Reconciliación entre la República de Uganda y el Ejército de Resistencia del Señor y su correspondiente Anexo (redactados tras la emisión de las órdenes de arresto contra los imputados), no cambian el escenario de inacción del estado por la ausencia de investigaciones y enjuiciamiento contra Joseph Kony y sus altos comandantes por los delitos que se les imputan ante la $\mathrm{CPI}^{27}$. La Sala de Apelaciones no encontró error en esta decisión ${ }^{28}$.

En el caso contra Germain Katanga y Mathieu Ngudjolo Chui, la Sala de Primera Instancia afirmó la admisibilidad del caso con base, entre otros fundamentos, en que la decisión del gobierno de la República Democrática del Congo de no investigar o enjuiciar los delitos presuntamente cometidos por el mismo, y dejar así que la CPI lo hiciera en su lugar, no daba lugar a ninguna de las causales de inadmisibilidad enumeradas en el art. 17(1) (a) a (c) del ER, y era coherente con el principio de "complementariedad" $"$. Esta interpretación fue confirmada por la Sala de Apelaciones ${ }^{30}$.

Por su parte, la Sala de Cuestiones Preliminares III concluyó que Jean-Pierre Bemba no estaba siendo enjuiciado en la República Centroafricana ("RCA") por los delitos alegados por la Fiscalía de la CPI, y que las autoridades judiciales de este estado habían abandonado todo intento de enjuiciarle, debido al reconocimiento de su inmunidad como vicepresidente de la RDC ${ }^{31}$. Por su parte, la Sala de Primera Instancia concluyó que la RCA no había tomado una decisión de "no enjuiciar" el caso contra Jean-Pierre Bemba en el sentido del art. 17(1)(b) del ER, sino que había promovido que su enjuiciamiento lo realizara la $\mathrm{CPI}^{32}$. La Sala también concluyó que el sistema judicial nacional de la RCA era "incapaz" de llevar a cabo dicho enjuiciamiento porque no tenía la capacidad de hacer frente a la complejidad y la amplitud del caso contra el acusado, y por tanto, dicho sistema, no se encontraba disponible debido a su falta de capacidad (art. 17(3) del ER).40 Esta interpretación ha sido también posteriormente confirmada por la Sala de Apelaciones ${ }^{33}$.

\footnotetext{
27 Ibid, p. 100. Vease también The Prosecutor vs Joseph Kony et al. Pre-Trial Chamber II., Decision on the admissibility of the case under article 19(1) of the Statute, ICC-02/04-01/05-377, 10 de marzo de 2009.

28 The Prosecutor. Joseph Kony et al., Appeals Chamber, Judgment on the appeal of the Defence against the "Decision on the admissibility of the case under article 19 (1) of the Statute" of 10 March 2009, ICC-02/04-01/05-408, 16 de septiembre de 2009. ${ }^{29}$ Olásolo Alonso \& Carnero Rojo, Admisibilidad de la situación en Kenia (supra n. 20), pp. 100-101. Véase también, The Prosecutor vs Germain Katanga, Pre-Trial Chamber I, Decision on the evidence and information provided by theProsecutionfor theissuance of a warrant of arrest forGermainKatanga, ICC- 01/04-01/07-4, 6 de julio de 2007, párrafos 17-21; The Prosecutor vs Matbieu Ngudjolo Chui, Pre-Trial Chamber I, Decision on the evidence and information provided by theProsecutionfor theissuance of a warrant of arrest forMathieu Ngudjolo Chui, ICC-01/04-02/07-3, 6 de julio de 2007, párrafos 17-22; y The Prosecutor vs Germain Katanga and Mathieu Ngudjolo Chui, Trial Chamber II, Reasons for the Oral Decision on the Motion Challenging the Admissibility of the Case (Article 19 of the Statute), ICC-01/04-01/07-1213-tENG, 16 de junio de 2009, párrafos. 77-79.

30 The Prosecutor vs Germain Katanga and Mathieu Ngudjolo Chui, Appeals Chamber, Judgment on the Appeal of Mr. Germain Katanga against the Oral Decision of Trial Chamber II of 12 June 2009 on the Admissibility of the Case, ICC-01/04-01/071497, 25 de septiembre de 2009, párrafos. 85-86.

31 Olásolo Alonso \& Carnero Rojo, Admisibilidad de la situación en Kenia (supra n. 20), p. 101. The Prosecutor vs Jean-Pierre Bemba Gombo, Pre-Trial Chamber III, Decision on the Prosecutor's Application for a Warrant of Arrest against Jean-Pierre Bemba Gombo, ICC- 01/05-01/08-14, 10 de junio de 2008, párrafo 21. Este fallo sobre la admisibilidad del caso no fue modifi cado por la Sala de Cuestiones Preliminares II en su decisión confirmando los cargos contra el Jean-Pierre Bemba en 2009. Véase, The Prosecutor vs Jean-Pierre Bemba Gombo, Pre-Trial Chamber II, Decision Pursuant to Article 61(7)(a) and (b) of the Rome Statute on the Charges of the Prosecutor Against Jean-Pierre Bemba Gombo, ICC-01/05-01/08-424, 15 de junio de 2009, párrafos 2526.

32 Olásolo Alonso \& Carnero Rojo, Admisibilidad de la situación en Kenia (supra n. 20), p. 102. Véase también, The Prosecutor vs Jean-Pierre Bemba Gombo, Pre-Trial Chamber III, Decision on the Admissibility and Abuse of Process Challenges, ICC-01/0501/08-802, 24 de junio de 2010, párrafos

241-249.

33 Olásolo Alonso \& Carnero Rojo, Admisibilidad de la situación en Kenia (supra n. 20), p. 102. Véase también, Jean-Pierre Bemba Gombo against the decision of Trial Chamber III of 24 June 2010 entitled "Decision on the Admissibility and Abuse of Process Challenges”, ICC-01/05-01/08-962, 19 de octubre de 2010, párrafos 74 and 107-109.
} 
III La aplicación del principio de complementariedad a las situaciones objeto de examen preliminar, y la función de este examen en la promoción del actuar de las jurisdicciones nacionales y el fortalecimiento del estado de derecho

En relación con el análisis de la admisibilidad de situaciones, destaca la distinta forma de proceder en las situaciones de Libia, Sudán, Kenia y Colombia. Con respecto a la situación en Libia el Consejo de Seguridad de las Naciones Unidas, en su resolución 1970, de 26 de febrero de 2011, refirió la situación de crisis existente en Libia desde el 15 de febrero de ese mismo año como consecuencia de la reacción de las fuerzas de seguridad del régimen de Gaddafi a las manifestaciones que desde aquella fecha se estaban llevando a cabo en las principales ciudades del país (Trípoli, Misrata y Benghazi). Apenas cinco días después, el 3 de marzo de 2011, la Fiscalía ponía fin a su examen preliminar y anunciaba la apertura de una investigación conforme al artículo 53 (3) (i) ER.

Una dinámica similar en gran medida se produjo en el caso de la apertura de la investigación en Darfur (Sudán). En su resolución 1593, de 31 de marzo de 2005, el Consejo de Seguridad de las Naciones Unidas remitió la situación de los tres estados de Darfur de la República de Sudán a la Fiscalía de la CPI, solicitándole el inicio de una investigación sobre el los delitos de genocidio, lesa humanidad y crímenes de guerra presuntamente allí cometidos. Tras dos meses de examen preliminar, la Fiscalía anunció la apertura de la investigación el 6 de junio de 2005. .

Notablemente distinto, fue el actuar de la Fiscalía de la CPI antes de que se iniciase la investigación más de 2 años después de la apertura del examen preliminar como consecuencia de las primeras comunicaciones sobre los delitos de lesa humanidad que se estaban presuntamente producido tras las elecciones presidenciales de diciembre de 2007 en seis de las ocho provincias de Kenia $^{34}$.

Así, en febrero de 2008, la Fiscalía de la CPI emitió un comunicado en el que dio a conocer que estaba realizando un examen preliminar de la violencia post-electoral en Kenia;

Kenia es un estado parte del Estatuto de Roma. La Fiscalía considera cuidadosamente toda la información referente a crímenes dentro de su competencia supuestamente cometidos en el territorio de estados partes o por nacionales de estados partes, sin consideración de las personas o del grupo que supuestamente hayan cometido el crimen ${ }^{35}$.

Un año después, la Fiscalía ratificó que estaba examinando la situación en Kenia, y aclaró que “continúa controlando si se están desarrollando procesos nacionales en relación con la violencia postelectoral de comienzos de 2008"36. El Fiscal también indicó que desde enero de 2008 había recibido 'comunicaciones' de individuos y organizaciones no gubernamentales al respecto conforme al art. 15 del $\mathrm{ER}^{37}$.

En julio de 2009 el Fiscal se reunió en la sede de la CPI con una delegación del gobierno keniano. Este último acordó transmitir al Fiscal un informe sobre las investigaciones y los enjuiciamientos que tuvieran lugar en Kenia en relación con la violencia post-electoral e informó al Fiscal que el parlamento keniano estaba debatiendo el establecimiento de un tribunal especial u otro mecanismo judicial para investigar y enjuiciar a los responsables de la violencia de 2008. Ambas partes acordaron que el gobierno de Kenia remitiría la situación al Fiscal conforme al art. 14 del ER si no se alcanzaba un acuerdo parlamentario para conseguir el "final de la impunidad de los máximos responsables por los crímenes más graves" dentro de los siguientes doce meses ${ }^{38}$.

\footnotetext{
34 Olásolo Alonso \& Carnero Rojo, Admisibilidad de la situación en Kenia (supra n. 20), pp. 105-108.

${ }^{35}$ Fiscalía de la CPI, "Declaración en relación con los acontecimientos en Kenia“, 5 de febrero de 2008.

${ }^{36}$ Hoja informativa de la Fiscalía de la CPI, "El Fiscal reafi rma que su Ofi cina sigue observando la situación en Kenia“, 11 de febrero de 2009.

${ }^{37}$ Idem.

${ }^{38}$ Fiscalía de la CPI, “Actas Acordadas de la reunión entre el Fiscal Moreno Ocampo y la delegación del Gobierno de Kenia“, 3 de julio de 2009.
} 
Como consecuencia del acuerdo con el gobierno de Kenia, a Fiscalía de la CPI recibió un informe del Fiscal General de Kenia sobre delitos cometidos durante la violencia post-electoral ${ }^{39}$. Además, la Comisión de Investigación sobre la Violencia Post-Electoral en Kenia (“Comisión Waki”) también transmitió a la Fiscalía los materiales que había recogido, junto con un sobre sellado que contenía una lista de personas que podrían estar implicadas en el desarrollo de dicha violencia ${ }^{40}$. Tras la recepción de estos materiales, el Fiscal de la Corte afirmó que:

Consideraremos en particular la existencia de procedimientos nacionales. Las autoridades kenianas están discutiendo opciones para establecer una corte nacional que enjuicie estos casos. Según el Estatuto de Roma, la responsabilidad principal para la investigación y el enjuiciamiento de estos crímenes es de Kenia. Las conclusiones de la Comisión Waki son importantes pero no vinculantes para mi Oficina; debo alcanzar una conclusión imparcial ${ }^{41}$.

Tras mantener consultas con el gobierno de Kenia, en septiembre de 2009, la Fiscalía de la "CPI sugirió un enfoque de tres vías para tratar la violencia post-electoral de comienzos de 2008 en Kenia. La CPI enjuiciaría a "los más responsables"; procesos nacionales establecidos por el parlamento de Kenia se encargarían de "otros responsables"; y una "Comisión de Justicia, Verdad y Reconciliación” sería creada en Kenia para esclarecer toda la historia de los acontecimientos pasados y para sugerir mecanismos de prevención de delitos similares en el futuro ${ }^{42}$.

En noviembre de 2009 no hubo suficiente quórum en el parlamento keniano para discutir la propuesta para el establecimiento de un tribunal nacional especial para la violencia post-electoral, pese a lo cual, el gobierno de Kenia decidió no remitir la situación en Kenia a la Fiscalía de la CPI. Como reacción a esta situación, la Fiscalía de la CPI, tras informar a las autoridades kenianas, notificó al Presidente de la CPI que tenía intención de pedir autorización judicial para comenzar a investigar la situación en Kenia según lo dispuesto en el art. 15(3) del ER ${ }^{43}$, e informó públicamente a las víctimas de la posibilidad de presentar sus observaciones a la Sala de Cuestiones Preliminares sobre si debería abrirse o no una investigación en relación con la violencia post-electoral sufrida en Kenia entre diciembre de 2007 y febrero de $2008^{44}$.

Una vez que la situación en Kenia fue asignada a la Sala de Cuestiones Preliminares $\mathrm{II}^{45}$, la Fiscalía de la CPI presentó el 26 de noviembre de 2009 ante esta Sala su petición de autorización para la apertura de la investigación. Sobre la base de informes públicos de las autoridades kenianas, de la ONU y de varias ONGs el Fiscal alegó en su petición que los actos cometidos en el territorio de Kenia a finales de 2007 y comienzos de 2008 eran constitutivos de delitos de lesa humanidad sobre los que la CPI tenía competencia (en particular, asesinato, violación y otras formas de violencia sexual, deportación o traslado forzoso de la población y otros actos inhumanos, todos ellos supuestamente cometidos en una estado parte tras su ratificación del ER ${ }^{46}$.

La Fiscalía sostuvo que los casos que surgieran de su investigación de la situación serían admisibles en ese momento porque no había pendientes investigaciones o procesos nacionales contra

\footnotetext{
39 Comunicado de prensa de la Fiscalía de la CPI, "El Fiscal de la CPI recibe materiales sobre la violencia post-electoral en Kenia“, 16 de julio de 2009.

40 Comunicado de prensa de la Fiscalía de la CPI, "La lista de nombres preparada por la Comisión Waki está en manos del Fiscal de la CPI“, 16 de julio de 2009.

${ }^{41}$ Comunicado de prensa de la Fiscalía de la CPI, "El Fiscal de la CPI recibe materiales sobre la violencia post-electoral en Kenia“, 16 de julio de 2009.

${ }^{42}$ Comunicado de prensa de la Fiscalía de la CPI, "El Fiscal de la CPI Apoya un Enfoque de Tres Vías para la Justicia en Kenia“, 30 de septiembre de 2009.

${ }^{43}$ Hoja informativa de la Fiscalía de la CPI, "Las autoridades de Kenia se muestran comprometidas a cooperar con la CPI cuando el Fiscal de la CPI les informa de que en diciembre pedirá a los jueces de la CPI la apertura de una investigación sobre la violencia post-electoral“", 5 de noviembre de 2009.

44 Situación in the Republic of Kenya, Presidency, Decision Assigning the Situación in the Republic of Kenya to Pre-Trial Chamber II, ICC-01/09-1-Anx, 6 de noviembre 2009; Anuncio público de la Fiscalía de la CPI, "Las víctimas de la violencia postelectoral en Kenia tienen 30 días para presentar observaciones ante la CPI en La Hava", 23 de noviembre de 2009.

45 Situación in the Republic of Kenya, Presidency, Decision Assigning the Situación in the Republic of Kenya to Pre-Trial Chamber II, ICC-01/09-1, 6 de noviembre de 2009.

46 Situacion in the Republic of Kenya, Offi ce of the Prosecutor, Request for authorisation of an investigation pursuant to Article 15, ICC01/09-3, 26 de noviembre de 2009.
} 
"los máximos responsables" por los delitos arriba mencionados. La Fiscalía declaró que según los informes de las autoridades kenianas, sólo un pequeño número de procedimientos penales por delitos menos graves había comenzado en Kenia en relación con los delitos presuntamente cometidos durante la violencia post-electoral. La Fiscalía sostuvo también que la información disponible en ese momento no indicaba la existencia de procedimientos nacionales en otros estados con competencia sobre la violencia post-electoral (art. 17(1)(a) a (c) del ER) ${ }^{47}$.Además, el Fiscal afirmó que dichos delitos eran lo suficientemente graves, teniendo en cuenta su número de víctimas, su organización y planificación y su impacto sobre las comunidades locales (art. 17(1)(d) del ER) ${ }^{48}$.

Antes de decidir sobre la petición de la Fiscalía, la Sala de Cuestiones Preliminares II procedió al análisis de la admisibilidad de la situación. A estos efectos, en febrero de 2010, la Sala solicitó información adicional a la Fiscalía sobre (i) los episodios que probablemente serían el centro de su investigación; (ii) los grupos de personas involucradas que presumiblemente sería investigados, y (iii) las investigaciones nacionales existentes, en caso de que hubiera alguna, con respecto a los "casos potenciales" conformados por los dos elementos anteriores ${ }^{49}$. Sobre la base de la información proporcionada por la Fiscalía y las observaciones recibidas de supuestas víctimas ${ }^{50}$, el 31 de marzo de 2010 la Sala de Cuestiones Preliminares autorizó la apertura de una investigación sobre la situación en Kenia $^{51}$.

El distinto tratamiento dado por la Fiscalía durante la fase de examen preliminar a las situaciones de Libia, Darfur (Sudán) y Kenia, se encuentra estrechamente relacionada con el potencial de los exámenes preliminares de la Fiscalía para incentivar a las autoridades nacionales de los estados afectados a poner fin a los delitos y proceder a su investigación y enjuiciamiento. De ahí, que frente al desafío frontal a la legitimidad de la CPI, y a la negativa de las autoridades de Libia y Sudán a proceder de manera independiente e imparcial en un plazo razonable a la investigación de los presuntos responsables de genocidio, delitos de lesa humanidad o crímenes de guerra que allí se estaban cometiendo, la respuesta inmediata de la Fiscalía haya sido la apertura en un espacio de días o semanas de la investigación (máxime después de que el Consejo de Seguridad de las Naciones Unidas acordara solicitar a la Fiscalía de la CPI que procediese a investigar dichos delitos).

Por su parte, en el caso de Kenia, la actitud más receptiva de las autoridades keniatas, y su inicial disposición para la creación de un tribunal especial a nivel nacional para que conociese de la violencia sistemática y a gran escala ocurrida tras las elecciones de diciembre de 2007, hizo que la Fiscalía tratara de impulsar, mientras ello parecía una opción viable, la creación de este tribunal o de otro mecanismo de justicia alternativa a nivel nacional, antes de proceder a solicitar a la Sala de Cuestiones Preliminares II la autorización para abrir la investigación. De hecho, sólo tras la constatación de la ausencia de una voluntad real de las autoridades nacionales de establecer los instrumentos necesarios para proceder a la investigación y enjuiciamiento de los responsables dicha campaña de violencia, es cuando la Fiscalía, casi dos años después del inicio del examen preliminar, es cuando decidió presentar su solicitud de autorización para la apertura de la investigación.

En este sentido, es importante señalar, que a pesar de la falta de resultados positivos de la estrategia de la Fiscalía de promover en tanto en cuanto fuera posible el establecimiento de los instrumentos necesarios a nivel nacional para que fuera la jurisdicción keniata la que se encargara de la investigación y enjuiciamiento de los delitos objeto de la violencia post-electoral de diciembre de2007 y enero/febrero de 2008, esta forma de operar ni contraviene el principio de complementariedad de la CPI ni presenta en todas las ocasiones resultados tan poco positivos como en el caso de la situación en Kenia.

\footnotetext{
${ }^{47}$ Ibid, párr. 55.

48 Ibid, párr. 56-59.

49 Situacion in the Republic of Kenya, Pre-Trial Chamber II, Decision Requesting Clarification and Additional Information, ICC01/09-15, 18 de febrero de 2010, párrafos 11 y 14.

50 Situacion in the Republic of Kenya, Registry, Public Redacted Version of Corrigendum to the Report on Victims" Representations, ICC-01/09-17-Corr-Red, 18 de marzo de 2010.

51 Situación en la República de Kenia, Sala de Cuestiones Preliminares II, Decisión Conforme al Artículo 15 del Estatuto de Roma relativa a la Autorización de una Investigación de la Situación en la República de Kenia, ICC-01/09-19, 31 de marzo de 2010.
} 
- Así como lo demuestran varios exámenes preliminares, incluidos aquellos relativos a las situaciones en Georgia ${ }^{52}$, Guinea ${ }^{53}$ y Palestina ${ }^{54}$, el Fiscal, además de recibir testimonio y buscar información de diversos tipos de fuentes ${ }^{55}$, puede: (i) enviar misiones a los estados afectados; (ii) recibir en su oficina de La Haya a delegaciones de gobiernos nacionales, representantes del poder judicial, líderes de la oposición y organizaciones no gubernamentales; (iii) recomendar aquellas medidas que deberían ser tomadas a nivel nacional para eliminar la amenaza de delitos atroces; (iv) discutir una estrategia de prevención con las Naciones Unidas, así como con otras organizaciones y estados interesados; (v) intercambiar información con actores nacionales e internacionales; y (vi) abordar en los medios de comunicación la evolución de los acontecimientos en los estados afectados, y el grado de cooperación de las autoridades nacionales ${ }^{56}$.

La utilización de canales diplomáticos y medios de comunicación permite llamar la atención de la Comunidad Internacional sobre los delitos que están siendo cometidos y la impunidad de sus presuntos autores, al tiempo que se subraya la posibilidad de que las autoridades nacionales puedan evitar su investigación y enjuiciamiento ante la CPI si se toman las medidas necesarias para que las jurisdicciones nacionales cumplan con su obligación de investigar y enjuiciar dichos delitos ellas mismas.

Es en sentido, la Fiscalía de la CPI, en su informe sobre exámenes preliminares de 13 de diciembre de 2011, ha afirmado que en el marco del examen preliminar que se sigue con respecto a la situación de Colombia desde el año 2005 se han adoptado las siguientes medidas:

La Oficina mantiene un diálogo constante con el gobierno de Colombia y ha recibido recientemente información actualizada sobre las actuaciones de las autoridades judiciales nacionales competentes. Más recientemente, el 21 de septiembre de 2011, el Fiscal se encontró con la nueva Fiscal General de Colombia, Vivian Morales. La autoridades colombianas han transmitido posteriormente nueva información actualizada sobre las actuaciones de JPL [Justicia y Paz] [ La Oficina ha intervenido en discusiones públicas sobre la aplicación del principio de complementariedad en Colombia. En una reunión bi-anual con las ONGs mantenida el 20 de octubre de 2010, la Oficina sostuvo una sesión sobre la complementariedad en el marco del examen preliminar en Colombia, con panelistas comentando la respuesta de las autoridades colombianas a la lucha contra la impunidad. La sesión se centró específicamente en torno a las actuaciones de JPL [] En mayo de 2011 en Londres, la Fiscalía participó en una conferencia de alto nivel, en la que estuvieron presentes un buen número de expertos, funcionarios colombianos, magistrados y representantes de ONGs, y que generó un saludable debate sobre el papel de la Oficina en el fortalecimiento del principio de complementariedad en Colombia [] La Oficina continuará examinando la situación y las actuaciones nacionales en Colombia. En este contexto, y conforme al principio de complementariedad positiva que ha adoptado, la Oficina da la bienvenida a los actuales esfuerzos del gobierno colombiano de buscar mayor apoyo internacional para las actuaciones judiciales nacionales y de promover la

\footnotetext{
52 En relación con el examen preliminar de la situación en Georgia, desde que el Fiscal de la CPI lo hizo público el 14 de agosto de 2008: (i) el ministro de justicia de Georgia ha visitado al Fiscal de la CPI en la Haya; (ii) 3817 comunicaciones individuales han sido enviadas al Fiscal de la CPI desde Rusia (un Estado no parte); (iii) el Fiscal ha solicitado información a los gobiernos de Rusia y de Georgia el 27 de agosto de 2008, y ambos han respondido; (iv) dos visitas a Georgia han sido realizadas por personal de la Fiscalía de la CPI en noviembre de 2008 y en junio de 2010; y (v) una visita a Rusia ha sido realizada por personal de la Fiscalía de la CPI en marzo de 2010. Véase, $\underline{w w w . i c c-}$ cpi.int/Menus/ICC/Structure+of +the+Court/Office+of +the+Prosecutor/Comm+And+Ref/Georgia/ , accedido por última vez el 20 de diciembre de 2010.

${ }^{53}$ En relación con el examen preliminar de la situación en Guinea, desde que el Fiscal de la CPI lo hizo público el 14 de octubre de 2009: (i) el Fiscal de la CPI ha sostenido en enero de 2010 consultas con el presidente de Burkina Faso (mediador del grupo de contacto para Guinea) y con el presidente de Senegal, a los efectos de asegurarse que ambos eran adecuadamente informados sobre el trabajo del Fiscal; (ii) dos visitas del personal de la Fiscalía a Guinea han tenido lugar en Febrero y Mayo de 2010 para reunirse entre otros con el Ministro de Justicia y varios magistrados. Véase a este respecto, www.icccpi.int/Menus/ICC/Structure+ + of + the + Court/Office+ + of + the+Prosecutor/Comm+and + Ref/Guinea/, accedido por última vez el 20 de diciembre de 2010.

${ }^{54}$ En relación con el examen preliminar de la situación en Palestina, una delegación de la Autoridad Nacional Palestina, y Representantes de la Liga Árabe visitaron respectivamente al Fiscal de la CPI el 15 y 16 de octubre de 2009, y el 11 de enero de 2010. Véase www.icc-cpi.int/Menus/ICC/Structure + of + the + Court/Office + of + the + Prosecutor/Comm + and + Ref/Palestine/ , accedido por última vez el 20 de diciembre de 2010.

55 Artículo 15 (2) ER, y reglas 104 y 105 de las Reglas de Procedimiento y Prueba.

56 Véase en este sentido, W. Burke-White, 'Implementing a Policy of Positive Complementarity in the Rome System of Justice', en Criminal Law Forum, Vol 19 (2008), pp. 59 y ss, p. 61; y C. Hall, 'Developing and Implementing an Effective Positive Complementarity Prosecution Strategy', en C. Stahn/G. Sluiter, The emerging practice of the International Criminal Court, Brill, Leiden, 2009, pp. 220 y ss.
} 
cooperación, tal y como ha explicado el actual presidente de Colombia D. Juan Manuel Santos, durante la novena Asamblea de los Estados Partes en diciembre de 2010 [] El nombramiento del juez español Baltasar Garzón, que ha trabajo para la Oficina como asesor en la Misión de Apoyo del Proceso de Paz en Colombia de la Organización de los Estados Americanos (OEA) es un ejemplo de la cooperación entre los Estados Partes, las organizaciones internacionales y la Oficina ${ }^{57}$.

Los exámenes preliminares constituyen, por tanto, una herramienta importante para potencial el estado de derecho a nivel nacional, y favorecer la dotación de las herramientas necesarias para que las jurisdicciones nacionales puedan llevar a cabo la investigación y enjuiciamiento de los delitos de la competencia de la CPI de manera independiente e imparcial y dentro de un plazo razonable. Es por ello que la propia Fiscalía de la Corte Penal Internacional ha subrayado que, en principio, no tienen una duración definida, sino que su extensión dependerá de las circunstancias específicas de cada situación:

El examen preliminar de la información disponible con respecto a una situación es realizado de manera comprehensiva y detallada. El Fiscal está obligado a continuar con dicho examen hasta el momento en el que la información muestra que existe, o no existe, una base razonable para proceder a la investigación. Por ejemplo, los criterios de complementariedad pueden requerir el monitoreo de ciertos procedimientos nacionales para determinar si los mismos se refieren a los delitos más graves y si son genuinos. En consecuencia, el tiempo y duración de las actividades a desarrollar durante el examen preliminar se tendrán que basar necesariamente en la situación de que se trate ${ }^{58}$.

En este contexto, todo incentivo a las autoridades nacionales para poner fin a la comisión de genocidio, delitos de lesa humanidad y crímenes de guerra, ha de ir acompañado de ${ }^{59}$ :

(i) La asistencia a dichas autoridades nacionales para que puedan cumplir con su deber de investigar y enjuiciar los delitos ya cometidos ("complementariedad positiva")

(ii) El reparto con la CPI, sobre todo cuando haya problemas serios de falta de capacidad, de la carga de investigar y enjuiciar dichos delitos ("complementariedad cooperativa")

De esta manera, se puede afirmar que el apoyo a los estados afectados receptivos para que fortalezcan sus sistemas nacionales de justicia y lleven a cabo sus propias actuaciones, constituye un elemento esencial del mandato de la CPI en cuanto que pilar básico de su mandato preventivo ${ }^{62}$.

\footnotetext{
${ }^{57}$ Fiscalía de la Corte Penal Internacional, Report on the Preliminary Examination Activities, de 13 de diciembre de 2011, párr. 83-86, disponible en http://www.icc-cpi.int/NR/rdonlyres/63682F4E-49C8-445D-8C13F310A4F3AEC2/284116/OTPReportonPreliminaryExaminations13December2011.pdf

${ }^{58}$ Fiscalía de la CPI, "Borrador de Políticas sobre Exámenes Preliminares", 4 de octubre de 2010 (supra nota 7), párr..83

59 Tanto la complementariedad positiva como la complementariedad cooperativa parecen haber sido, en gran medida, implícitamente confirmadas por la decisión de la Sala de Apelaciones de 22 de junio de 2009 en el caso Katanga y Ngudjolo. Véase Prosecutor vs Germain Katanga and Mathieu Ngudjolo Chui, Decision of the Presiding Judge of the Appeals Chamber in the appeal of Germain Katanga against the Decision of Trial Chamber II of 12 June 2009 on the Admissibility of the Case, Appeals Chamber, ICC-01/04-01/07-1286, de 10 de julio de 2009.

${ }^{60}$ Véanse W Burke-White, 'Implementing a Policy of Positive Complementarity in the Rome System of Justice' en Criminal Law Forum, Vol 19 (2008), pp. 59 y ss, p. 61; y C Hall, 'Developing and Implementing an Effective Positive Complementarity Prosecution Strategy' en C. Stahn/G. Sluiter (coords.), The emerging practice of the International Criminal Court, Brill, Leiden, 2009, pp. 220 y ss. Véase también, M.E. Cross/S. Williams, 'Recent Developments at the ICC: Prosecutor vs Germain Katanga and Mathieu Ngudjolo Chui: A Boost for Co-operative Complementarity?', en Human Rights Law Review, Vol 10 (2010), pp. 336 y ss, p. 339.

61 A. Cassese, 'The Rome Statute: A Tentative Assessment', en Cassese et al. (coords.), The Rome Statute of the International Criminal Court: A Commentary, Oxford University Press, Oxford, 2002, p.1901 y ss, p. 1906; C. Kress, "Self-Referrals" and "Waivers of Complementarity": Some Considerations in Law and Policy', en Journal of International Criminal Justice, Vol 2 (2004), pp. 944 y ss, pp. 947-948; y F. Gioia, 'State Sovereignty, Jurisdiction, and "Modern” International Law: The Principle of Complementarity in the International Criminal Court', en Leiden Journal of International Law, Vol. 19 (2006), pp. 1095 y ss, p. 1115.

${ }^{62}$ H. Oráoslo Alonso, "La función de la Corte Penal Internacional en la prevención de delitos atroces mediante su intervención oportuna: de la doctrina de la intervención humanitaria y de las instituciones judiciales ex post-facto al concepto de responsabilidad de proteger y la intervención oportuna de la Corte Penal Internacional", en H. Oráoslo Alonso, Ensayos de Derecho Penal y Procesal Internacional, Tirant lo Blanch \& Instituto Ibero.-Americano de la Haya (IIH), Valencia, 2011 (reimpreso
} 
A este respecto, William Burke-White ${ }^{63}$ y Christopher Hall ${ }^{64}$ han afirmado que la Fiscalía puede recurrir al tipo de medidas que acabamos de ver para cumplir con este mandato a través de sus exámenes preliminares e investigaciones. En particular, el Fiscal puede entrenar a los actores jurídicos nacionales en la investigación y el enjuiciamiento de delitos atroces, y asistirles en el establecimiento de programas de diversa índole, incluyendo programas de protección de víctimas y testigos, y administración y gestión de la información. Así mismo, puede monitorear el desarrollo de las actuaciones nacionales y dar su parecer al respecto, así como trabajar en coordinación con los otros órganos de la CPI para incrementar la eficacia de las medidas preventivas adoptadas.

En cuanto a los resultados de esta forma de operar, y a pesar de la ausencia todavía de pruebas concluyentes, existen indicios de que el examen preliminar en Afganistán contribuyó a que la OTAN, y en particular los Estados Unidos, definiesen de manera más estricta las condiciones para el lanzamiento de bombardeos aéreos ${ }^{65}$. Los Estados Unidos también parecen haber reafirmado su compromiso de recurrir a sus propios mecanismos de investigación y enjuiciamiento internos ${ }^{66}$, lo que parece haber provocado la apertura en abril de 2010 de una investigación de alto nivel con respecto a las muertes de civiles presuntamente provocadas por fuerzas especiales norte-americanas ${ }^{67}$.

Por su parte, el examen preliminar en Iraq, que comenzó a raíz de las numerosas comunicaciones individuales recibidas por el Fiscal desde el año 2003, fue cerrado debido a las actuaciones iniciadas por el Reino Unido con respecto a todas y cada una de las instancias en las que nacionales británicos pudieron verse involucrados en la comisión de crímenes de guerra ${ }^{68}$.

Ahora bien, la situación donde se pueden apreciar resultados más positivos hasta el momento, sobre todo a la luz de las sentencias que sobe la vinculación de parlamentarios y gobernadores aforados con los grupos paramilitares en Colombia viene dictando la Sala de Casación Penal de la Corte Suprema de Justicia desde 2009 ("Sala de Casación Penal”), y las comprehensivas sentencias de primera instancia que en el último año ha emitido la Sala de Conocimiento de Justicia y Paz del Tribunal Superior de Bogotá (“SJP”) sobre la creación, consolidación y expansión de los grupos paramilitares en Colombia. Veamos a continuación la manera en que la estrategia de la Fiscalía durante el examen preliminar de la situación en Colombia ha venido operando desde su apertura en 2005.

\section{El examen preliminar de la situación en Colombia y el actuar de los órganos jurisdiccionales (2005-2012).}

Esta situación se pone de manifiesto al analizar el devenir de los acontecimientos en Colombia, y eso que las investigaciones sobre los paramilitares desmovilizados en Colombia a partir del año $2003^{69}$

en 2012 en Medellín, Colombia, por la editorial Dike, la Unión Europea y el Ministerio de la Justicia y el Derecho de Colombia), p. 50, 52 y 54 [en adelante: Oráoslo Alonso, Función de prevención de la CPI]

${ }_{63}$ W. Burke-White, 'Implementing a Policy of Positive Complementarity in the Rome System of Justice', en Criminal Law Forum, Vol 19 (2008), pp. 59 y ss, p. 61.

${ }^{64}$ C. Hall, 'Developing and Implementing an Effective Positive Complementarity Prosecution Strategy' en C. Stahn/ G. Sluiter (coord.), The emerging practice of the International Criminal Court, Brill, Leiden, 2009, pp. 220 y ss.

65 Véase D. Schwammenthal, 'Prosecuting American 'War Crimes", en The Wall Street Journal, Section Opinion Europa, The Hague, 26 de noviembre de 2009. Véase también, D. Filkins 'U.S. Tightens Airstrike Policy in Afghanistan' en The New York Times, section Asia-Pacific, 21 de junio de 2009.

${ }^{66}$ Véase E. Barbour/M.C. Weed, 'The International Criminal Court (ICC): Jurisdiction, Extradition, and U.S. Policy', en Congressional Research Service, de 16 de marzo de 2010 (disponible en http://assets.opencrs.com/rpts/R41116 20100316.pdf, accedido por última vez el 20 de diciembre de 2010), p. 15.

67 Véase L King, 'Inquiry puts Spotlight on U.S. Special Forces in Afghanistan' The Los Angeles Times (Los Ángeles, 9 de abril de 2010), refiriéndose a una investigación de alto perfil abierta por el ejército norteamericano en abril de 2010 sobre las presuntas muertes de civiles causadas por las fuerzas especiales que, hasta entonces, habían sido ocultadas al público.

${ }^{68}$ Fiscalía de la CPI, 'OTP Response to communications received concerning Iraq', de 9 de febrero de 2010, disponible en www.icc-cpi.int/NR/rdonlyres/04D143C8-19FB-466C-

AB774CDB2FDEBEF7/143682/OTP letter to senders_re Iraq_9 February 2006.pdf, accedido por última vez el 20 de diciembre, p. 9.

${ }^{69} \mathrm{El}$ proceso de desmovilización fue resultado del acuerdo de Santo Fe de Ralito firmado el 15 de julio de 2003. Dicho acuerdo se produjo entre el gobierno nacional de Colombia y las AUC. 
no comenzaron hasta que la Corte Constitucional colombiana se pronunció en mayo de 2006 sobre la constitucionalidad de la ley de Justicia y Paz, pieza clave del proceso de desmovilización ${ }^{70}$. Poco después, el Fiscal de la CPI hizo público su examen preliminar ${ }^{71}$, y en octubre de 2007 y agosto de 2008 realizó sendas visitas a Colombia ${ }^{72}$. Con posterioridad, en el año 2010, tanto el Fiscal General de Colombia, como una amplia representación de la Sala de Casación Penal, visitaron la Fiscalía de la Corte $^{73}$, y en septiembre de 2011 el Fiscal de la CPI realizó una nueva vista a Colombia donde se encontró la entonces recién nombrada Fiscal General, Vivianne Morales ${ }^{74}$.

Apenas tres meses después de esta última visita, la Fiscalía publicaba su informe sobre actividades en los exámenes preliminares en el explicaba que había recibido 86 comunicaciones en relación con Colombia, de las que 17 se referían a hechos sobre los que la CPI no tenía jurisdicción, que las otras 69 estaban siendo analizadas como parte del examen preliminar sobre Colombia que la Fiscalía desarrolla desde $2005^{75}$. A continuación se mencionaba a los principales actores involucrados en el conflicto que ha asolado Colombia durante décadas, haciendo hincapié en la reducción del poder de los grupos paramilitares en los últimos años a través del proceso de desmovilización auspiciado por la Ley de Justicia y Paz, si bien observaba que un cierto número de desmovilizados había vuelto a tomar las armas reconfigurando unidades de menor tamaño y una alto grado de autonomía ${ }^{76}$. Finalmente, se procedía a un análisis numérico de las actuaciones desarrolladas en los últimos años por los órganos jurisdiccionales colombianos, en el que la Fiscalía de la CPI subrayaba los siguientes datos:

(a) Colombia tiene un aparato judicial que se encuentra disponible para investigar y enjuiciar los delitos de lesa humanidad y crímenes de guerra cometidos desde la entrada en vigor del Estatuto de Roma para este estado ${ }^{77}$.

(b) Los órganos jurisdiccionales colombianos están desarrollando actuaciones contra (i) dirigentes de los grupos armados al margen de la ley involucrados en los delitos; (ii) dirigentes paramilitares; (iii) oficiales de las fuerzas armadas y de la policía; (iv) políticos vinculados con dichos grupos armados; y (v) sospechosos de haber incurrido en casos de falsos positivos ${ }^{78}$

(c) Un número importante de altos dirigentes de los grupos de guerrillas de las Fuerzas Armadas Revolucionarias de Colombia (FARC) y Ejército de Liberación Nacional (ELN) ha sido sentenciado o imputado en ausencia por delitos de la competencia de la $\mathrm{CPI}^{79}$;

(d) Se han presentado 451 escritos de acusación contra paramilitares desmovilizados en el proceso de Justicia y Paz, y han sido condenados once comandantes paramilitares (si bien entre septiembre de 2008 y marzo de 2009, las autoridades colombianas extraditaron a 29 miembros de grupos paramilitares, entre los que se encontraban diez de sus máximos dirigentes, a los EEUU por cargos relativos al narcotráfico; siete de los comandantes paramilitares extraditados han sido condenados por delitos ordinarios en

\footnotetext{
70 Véase la Sentencia de la Corte Constitucional Colombia, C-370/2006, de 18 de mayo de 2006. Véase también, J.E. Arvelo 'International Law and Conflict Resolution in Colombia: Balancing Peace and Justice in the Paramilitary Demobilization Process', en Georgetown Journal of International Law, Vol. 77 (2006), pp. 411 y ss.

${ }^{71}$ Véase www.icc-cpi.int/Menus/ICC/Structure+of + the+Court/Office + of + the+Prosecutor/Comm + and + Ref/Colombia , accedido por última vez el 20 de diciembre de 2010.

${ }^{72}$ Idem.

73 Olásolo Alonso, Función de prevención de la CPI (supra n. 62), p. 76.

${ }^{74}$ Fiscalía de la Corte Penal Internacional, Report on the Preliminary Examination Activities, de 13 de diciembre de 2011 (supra n. 57), párr. 85.

${ }^{75}$ Fiscalía de la Corte Penal Internacional, Report on the Preliminary Examination Activities, de 13 de diciembre de 2011 (supra n. 57), párr. 61.

76 Ibid, párr. 63 y 64.

77 Ibid, párr. 74.

78 Idem.

79 Ibid, párr. 75.
} 
relación con hechos presuntamente constitutivos de delitos de la competencia de la $\mathrm{CPI})^{80}$;

(e) Desde agosto de 2011, cincuenta y nueve senadores, cuarenta y ocho miembros de la Cámara de Representantes, 33 gobernadores, 252 alcaldes, y 84 autoridades locales están siendo investigados a raíz de las confesiones realizadas por los paramilitares desmovilizados conforme a la Ley de Justicia y Paz. Además, se han emitido 16 condenas por concierto para delinquir con los grupos paramilitares y asesinato, lo que ha supuesto en algunas ocasiones penas de cuarenta años ${ }^{81}$;

(f) Se están desarrollando actuaciones contra varios miembros y altos cargos de los servicios de inteligencia civil (Departamento Administrativo de Seguridad, DAS) en relación con escuchas telefónicas ilegales generalizadas, falsos positivos y vinculación con el paramilitarismo; ${ }^{82}$

(g) A raíz del proceso de Justicia y Paz se han iniciado actuaciones contra 191 oficiales del ejército colombiano y 57 miembros de menor rango, así como contra 121 oficiales de la policía nacional y 128 integrantes de la misma de menor graduación (seis oficiales del a marina se han visto afectados también por las mismas) ${ }^{83}$.

Ahora bien, tanto en el informe de la Fiscalía de la CPI de 13 de diciembre de 2011, como en otros informes presentados por organizaciones que monitorean el desarrollo de las actuaciones nacionales en Colombia (así, por ejemplo, el 31 de mayo de 2012, la organización abogados sin fronteras de Canadá presentó el último de estos informes en una mesa redonda en La Haya junto con miembros de la Federación Internacional de los Derechos del Hombre), se puede observar la falta de análisis detallado de las decisiones judiciales a las que se refieren. De esta manera, los informes se centran, en gran medida, en la presentación de cifras sobre el progreso (o la falta de progreso) de las actuaciones nacionales, limitándose por tanto a lo que se podría denominar como una "guerra de cifras", en lugar de profundizar en el análisis jurídico de las decisiones a que se refieren. En otras palabras, se deja a un lado la cuestión relativa al detalle y precisión con que dichas decisiones describen la composición y el accionar de las estructuras armadas involucradas, y de los actores políticos, económicos, militares y administrativos que favorecieron su creación, consolidación y expansión.

En nuestra opinión, esta aproximación nos parece inadecuada, puesto que es la detallada contextualización de los distintos grupos armados al margen de la ley, y la investigación de los vínculos que los mismos pudieran tener con las distintas administraciones públicas, lo que realmente nos va a permitir determinar si las actuaciones judiciales nacionales van dirigidas a sacar a la luz la forma de organización, modus operandi y apoyo externo que permitió a los grupos paramilitares ejercitar a principios de los años 2000 un control tan amplio sobre una buena parte del territorio de Colombia, que el propio Salvatore Mancuso (comandante del Bloque Norte de las Autodefensas Unidas de Córdoba y Urabá, ACCU) llegó a afirmar que las autodefensas terminaron por conformar un "estado de facto", ejercieron el gobierno, cobraron impuestos, decidieron conflictos e incluso "hasta el poder eclesiástico fue reemplazado por nosotros en la zona" ${ }^{84}$ En el mismo sentido, Iván Roberto Duque, alias "Ernesto Báez", comandante político del Bloque Central Bolívar, ha sido todavía más explicito al señalar que:

Las autodefensas construyeron unos Estados y a través de esos Estados administraron justicia, ejercieron autoridad, se dictaron leyes, se estableció un sistema impositivo de contribuciones, se pagó servicio

\footnotetext{
${ }^{80}$ Ibid, párr. 76.

${ }^{81}$ Ibid, párr. 78.

82 Ibid, pàrrs. 77 y 79 .

83 Ibid, párr. 80.

${ }^{84}$ Conocimiento de Justicia y Paz del Tribunal Superior de Justicia de Bogotá, Decisión de control de legalidad en el caso contra Gian Carlos Gutiérrez Suárez, alias El Tuerto (Bloque Calima), caso (radicado), núm. 110016000253200880786, de 30 de septiembre de 2010, párr. 120 [en adelante: control de legalidad en el caso contra alias el Tuerto].
} 
militar, es decir todo lo que se hace en un Estado de derecho...Cuando en esas regiones el jefe del Estado de hecho mandaba llamar a alguien y ese alguien no se presentaba de inmediato, la amenaza era contundente y clara: o se presenta o mandamos por usted ${ }^{85}$.

Por esta razón, ya desde el año 2009, la Sala de Casación Penal de la Corte Suprema de Colombia ("Sala de Casación Penal) subrayó la importancia de centrar las investigaciones y enjuiciamientos relativos a grupos paramilitares en: (i) el patrón de delitos de lesa humanidad y crímenes de guerra a que se vio sometida la población civil; y (ii) la estructura, composición y apoyo externo recibido por los grupos paramilitares que cometieron estos delitos en su proceso de creación, consolidación y expansión ${ }^{86}$ Estas directrices jurisprudenciales fueron reflejadas en el Protocolo para la Presentación de Medios de Prueba adoptado el 23 de agosto de 2010 por la SJP.

De ahí, que más allá de las cifras ofrecidas por unos y otros, lo que resulta realmente relevante a la hora de analizar el funcionamiento del principio de complementariedad en una situación como la colombiana, es profundizar en un análisis detallado del contenido de las decisiones emitidas hasta el momento por sus órganos jurisdiccionales. Es precisamente esta tarea la que, a pesar de las limitaciones de espacio ${ }^{87}$, nos proponemos realizar en las próximas secciones.

\section{A. Análisis del fenómeno de la "para-política" en los hechos declarados probados por la Sala de Casación Penal y la SJP}

En desarrollo de los criterios de investigación y enjuiciamiento establecidos en su propia jurisprudencia, la Sala de Casación Penal, a raíz de las confesiones (versiones libres) realizadas a partir del año 2007 por miembros de grupos paramilitares desmovilizados conforme a la Ley 975 de Justicia y $\mathrm{Paz}$, ha procedido a la investigación y enjuiciamiento en única instancia de aquellos miembros de la Cámara de Representantes y del Senado, así como de aquellos gobernadores (todos ellos aforados), que formaron parte, o contribuyeron a la formación, consolidación y expansión de los grupos paramilitares. Este fenómeno, conocido como "parapolítica", afectó a amplios sectores de la clase política local, regional y nacional y ha sido definido por la propia Sala de Casación Penal en auto de 18 de noviembre de 2009 y sentencia de 23 de febrero de 2010 de la siguiente manera:

Como es ya de público conocimiento, la agrupación paramilitar se fijó como meta ingresar el mayor número de candidatos a todas las corporaciones públicas, siendo indiferentes los partidos políticos o vertientes representados por ellos, en tanto lo relevante era el compromiso con la expansión del proyecto paramilitar ${ }^{88}$. Ello determinó insólitas alianzas entre grupos tradicionalmente opuestos ideológicamente, o entre enconados enemigos que representaban distintas vertientes de un mismo partido ${ }^{89}$.

Esta situación ha llevado a la Sala de Casación Penal a declarar que:

Las evidencias históricas y probatorias que ahora hacen parte de los hechos notorios, revelan de manera incontrastable que el gran alcance estaba dado en apoderarse del Estado en su conjunto mediante la imposición y nombramiento de candidatos a diversos cargos públicos de la más alta jerarquía, valga decir, financiar, apoyar, controlar, las elecciones populares en los municipios, departamentos, a nivel nacional, propósito que se puso a andar a través de los diferentes pactos delictuosos que se firmaron de manera distribuida a lo largo y ancho del

\footnotetext{
85 Ibid, párr. 122.

${ }^{86}$ Ver, entre otras, las decisiones de la Sala de Casación Penal de la Corte Suprema de Colombia en los casos contra: (i) Wilson Salazar Carrascal, alias, El Loro, Caso Núm. 31539, de 31 de julio de 2009; y (ii) Gian Carlo Gutiérrez Suarez, alias El Tuerto, Caso Núm. 32022, de 21 de septiembre de 2009.

87 H. Olásolo Alonso, Autoría y participación en Derecho penal internacional, Temis, Univesidad Sergio Arboleda \&Instituto Iberoamericano de la Haya para la Paz, los Derechos Humanos y la Justicia Internacional (IIH), Bogotá, 2012 (en prensa).

${ }^{88}$ Corte Suprema de Justicia, Sala de Casación Penal, sentencia condenatoria en el caso contra el ex senador Álvaro Alfonso García Romero, caso (radicado) núm.32805, de 23 de febrero de 2010 [en adelante: sentencia en única instancia contra el senador Álvaro Alfonso García Romero]

${ }^{89}$ Idem.
} 
territorio colombiano". Y se agregó que todo ello ocurría dentro de un plan dirigido a la "refundación de la patria, de destrucción y construcción de un para-estado mafioso"90.

Por su parte, la SJP ha señalado en relación con las alianzas entre grupos paramilitares y la clase política colombiana:

Estas alianzas no se limitaron a relaciones entre Bloques regionales y las elites locales, sino que incluyeron acuerdos de carácter nacional con el fin de "Refundar el País y hacer un nuevo contrato social", estrategia de la cual existe evidencia documental, como el "Pacto Santa Fé de Ralito", suscrito hace ya cerca de diez años, en el municipio de Tierra alta, Córdoba, que implicó el apoyo a líderes nacionales en sus campañas al Congreso de la República. Como este pacto, ocurrieron diversos acuerdos entre grupos paramilitares y elites regionales; conocidos por la opinión pública y estrados judiciales son: El pacto de Chivolo, el pacto del Magdalena, el pacto de Granada, el pacto de Puerto Berrio, la denominada Reunión de Coordinación, el pacto de la Lorena, el denominado grupo “sindicato", los pactos de Pivijay y el pacto del Eje cafetero y Caldas"1.

Con respecto al llamado "Pacto de Santa Fé del Ralito", la Sala de Casación Penal, en el caso contra los ex senadores Juan Manuel López Cabrales y Reginaldo Montes Álvarez, ha afirmado:

Es muy posible que en un principio ese fenómeno obedeciera a la muy cuestionable pretensión de sustituir al Estado democrático para enfrentar un "estado guerrillero". Sin embargo, la dinámica del conflicto demuestra que no fue así. Al contrario, en nombre de una concepción fundamentalista de ultra derecha que no permitía la menor disidencia, luego de imponer “orden”, las autodefensas armadas decidieron incidir en lo político, en lo económico y en lo espiritual. [...] En ese contexto, cuyas manifestaciones de violencia no se pueden desconocer, Salvatore Mancuso, alias "Santander Lozada" y otros líderes de las autodefensas, convocaron a dirigentes políticos del más elevado nivel, a otros con influencia regional, y a empresarios y ganaderos a la denominada reunión de Ralito que se llevó a cabo el 23 de julio de 2001, sesión en la cual después de que dos conferencistas extranjeros expusieran su visión acerca de los conflictos políticos en un mundo globalizado, se suscribió un acuerdo "confidencial y secreto" en el que la "refundación de la patria" y la pretensión de firmar un "nuevo pacto social" fueron los ejes temáticos del documento mencionado ${ }^{92}$.

A la reunión de Santafé de Ralito y al documento suscrito se ha pretendido restarles importancia con el argumento de que allí no se habló de nada distinto a la posibilidad de avanzar hacia un proceso de paz y porque el texto no expresa nada diferente a una proclama afín con esa temática, tal cual ocurriera con ocasión del "acuerdo del Nudo del Paramillo". Sin embargo, el tema de la paz es un "acto de gobierno" cuya dirección le corresponde de manera "exclusiva" al Presidente de la República como responsable del orden público, razón por la cual lo menos que se podía esperar ante la supuesta "bondad" de la propuesta era que el senador Montes Álvarez, miembro de la Comisión de Paz, hubiese informado de ello al Gobierno Nacional, y por supuesto también el doctor López Cabrales [ Sin embargo, no por haber escuchado a algunos expositores disertar sobre los conflictos internos en otras latitudes ni por las alusiones que se hacen al Preámbulo y a otros artículos de la Constitución Política, el documento de Santafé de Ralito puede tenerse como un documento que nada dice a la finalidad de promover a un grupo ilegal. Por el contrario, aparte del "elegante toque de filantropía" al que pareciera invitar por su referencia a cláusulas del ordenamiento superior, lo que allí se consigna es un acuerdo para "refundar la patria" entre quienes al representar la institucionalidad no tenían por qué comprometerse a hacerlo por fuera de una política de Estado, y grupos al margen de la ley interesados en que se reconocieran sus acciones violentas como actos políticos [...] De manera que el pacto de Santafé de Ralito corresponde a un quehacer y a una estrategia de las autodefensas empecinadas en lograr acuerdos con la clase política para impulsar la expansión de sus acciones, y de allí que los convidados no fueran ciudadanos del común sin posibilidades de agenciar en ese propósito, sino personas con capacidad para actuar ante instancias del orden nacional o con posibilidad de hacerlo - como de hecho lo hicieron Eleonora Pineda, Rocío Arias y Miguel de la Espriella -, pero sobre todo con poder para influir en la vida de la región, propiciando de esa manera que el paramilitarismo hiciera posible su pretensión de incidir en las políticas públicas ${ }^{93}$.

\footnotetext{
${ }^{90}$ Corte Suprema de Justicia, Sala de Casación Penal, auto de 18 de noviembre de 2009, radicación 28540.

${ }^{91}$ Sentencia de la Sala de Conocimiento de Justicia y Paz de Bogotá de 16 de diciembre de 2011 en el caso contra el comandante del Bloque Elmer Cárdenas Fredy Rendón Herrera, alias El Alemán, caso (radicado), núm 110016000253200782701, párr. 487 [en adelante: sentencia de primera instancia en el caso contra alias El Alemán], párr. 486.

92 Corte Suprema de Justicia, Sala de Casación Penal, Sentencia contra de los senadores Juan Manuel López Cabrales y Reginaldo Montes Álvarez, caso (radicado) núm. 26942, de 25 de noviembre de 2008.

${ }^{93}$ Idem.
} 
En relación con el pacto de Pivijay, la Sala Casación de Penal ha declarado su conclusión por el Bloque Norte (comandado por alias Jorge 40), y políticos del departamento del Cesar, y que el mismo benefició a senadores como Álvaro Araujo Castro ${ }^{94}$. En palabras de la propia Sala de Casación Penal:

Y es que demostrado que los resultados electorales del 10 de marzo de 2002 favorables a Álvaro Araújo Castro fueron producto de acuerdos celebrados con "Jorge 40", quien había convenido lo mismo con otros candidatos al Congreso, por lo que fue necesario dividir el departamento del Cesar, asignar zonas a los postulados para beneficiarlos, y a su vez ejercer la intimidación de la población dominada por el bloque norte de las AUC que se extendía aproximadamente al 70\% de ese territorio, a fin de que se depositaran los votos por aquellos candidatos a quienes se había destinado la respectiva $\operatorname{comarca}^{95}[\ldots]$ no solamente la violencia física y moral a que fue sometida la comunidad impidiéndosele optar libremente por la alternativa política de sus preferencias, cuando dan cuenta de los asesinatos, inclusive de copartidarios del acusado, así como de las amenazas, desplazamientos y demás actividades ilegales que el grupo armado ilegal perpetró, precisamente para lograr el resultado electoral acordado, pues la forma en que ese organismo de poder actuaba era de conocimiento público en la región, y, por lo tanto, también del acusado, quien de acuerdo con su propia versión, tuvo la oportunidad de advertirlo dado el recorrido que hacía del departamento en su gestión pública, aún antes de desarrollar su campaña política al Senado 2002, época ésta en la que igualmente pudo hacerlo sin contratiempo, a diferencia de otros aspirantes que ni siquiera se atrevían a visitar poblaciones alejadas de Valledupar, como lo señaló Luis Alberto Monsalvo Gnecco, y de aquellos que al desconocer las amenazas por ir en contravía de lo determinado por el grupo armado, se convirtieron en sus víctimas ${ }^{96}$.

La Sala de Casación Penal también ha afirmado que el Pacto del Eje Cafetero y Caldas fue concluido entre el Bloque Cacique Pipintá ligado al Bloque Central Bolívar y los líderes regionales, beneficiando, entre otros, a los representantes a la Cámara Dixon Ferney Tapasco y Emilio Enrique Rangel ${ }^{97}$. Según explica la Sala:

La sectorización con fines electorales y su refrendación no tendría mayor relevancia en circunstancias normales; más su desvalor surge desde el momento en que se refrenda, no ya con los líderes del partido, sino con las autodefensas, el compromiso de garantizar la consolidación de la fuerza electoral afecta al grupo armado ilegal, que veía en el norte de Caldas una zona que le garantizara hacia el futuro a "Báez", el afianzamiento de la línea política del paramilitarismo ${ }^{98}$ [ Ahora bien, pese a que la naturaleza ilícita de los acuerdos, por la estructura del tipo penal, no requiere que el mismo se materialice, sí es esencial que cuando el consenso gira alrededor de temas electorales, el asunto pueda verificarse a través de datos objetivos, tal como se ha dicho en otras ocasiones ${ }^{99}$. En ese orden no puede pasar desapercibido el hecho de que Dixon Ferney Tapasco Triviño hubiese aceptado sin mayores discusiones la inclusión del estudiante Sánchez en la lista del partido, algo sin duda muy difícil de concebir dentro de la dinámica proselitista, por lo cual se ofrece mucho mas admisible la explicación de alias "Diana", según la cual fue "Ernesto Báez" quien le brindó apoyo a un muchacho sin mayor experiencia política, y quien sin ese respaldo no habría tenido la oportunidad para aspirar como candidato a la Cámara en una lista cuyo éxito estaba garantizado, primero por el respaldo de los jefes liberales y segundo por el inconfesable apetito de poder de las autodefensas ${ }^{100}$.

Con respecto al pacto del Chivolo, ha sido la SJP la que ha concluido que el mismo se llevó a cabo el 28 de septiembre de 2000 por iniciativa del comandante del Bloque Norte, alias Jorge 40, con el fin de controlar los departamentos de la Guajira, Cesar y Magdalena y seleccionar a los candidatos a gobernaciones y alcaldías $^{101}$. Según la Sala, del mismo fue electo el gobernador José Domingo Dávila Armenta, quien posteriormente ha sido condenado por la Sala de Casación Penal por sus vínculos con grupos paramilitares ${ }^{102}$.

\footnotetext{
${ }^{94}$ Corte Suprema de Justicia, caso (radicado) núm. 27.032.

95 Corte Suprema de Justicia, Sala de Casación Pena, sentencia en el caso contra el ex senador Álvaro Araujo Castro, caso (radicado) núm. 27032, de 18 de marzo de 2010.

${ }^{96}$ Idem.

${ }^{97}$ Corte Suprema de Justicia, caso (radicado) núm. 26584.

${ }^{98}$ Corte Suprema de Justicia, Sala de Casación Penal, caso contra el ex representante a la cámara Dixon Ferney Tapasco Triviño, caso (radicado) núm. 26584, de 3 de febrero de 2010.

${ }^{99}$ Idem.

${ }^{100}$ Idem

101 Sentencia de primera instancia contra alias El Alemán (supra n. 91), párr. 486, nota al pie 246.

102 Idem.
} 
En definitiva, debido a que este fenómeno de connivencia entre grupos paramilitares y miembros de la clase política nacional, regional y local colombiana (que según la Sala de Casación Penal y la propia SJP se extendió por buen parte del país), afectó a personas aforadas que, por razón de su cargo, sólo podían ser investigadas y enjuiciadas por la Sala de Casación Penal, no puede sorprender la enorme relevancia de:

(i) La función de este órgano jurisdiccional en la exposición ante la sociedad nacional e internacional de este fenómeno; y

(ii) La jurisprudencia que ha generado en relación con la formas de responsabilidad penal de quienes desde la política han trabajado "codo con codo" con grupos paramilitares (e incluso en ocasiones han formado parte de su aparato político).

\section{B. Análisis del fenómeno de la "para-economía" en los hechos declarados probados por la Sala de Casación Penal y la SJP}

Las actuaciones adelantadas por la Sala de Casación Penal y la SJP a raíz de las confesiones presentadas desde 2007 por los paramilitares desmovilizados reflejan el notable impacto que tuvieron gremios económicos y grupos empresariales nacionales, así como multinacionales de terceros países, en la promoción y financiación de los grupos paramilitares (fenómeno conocido como "paraeconomía").

Al no tener la condición de aforados, ni haberse desmovilizado conforme a la Ley 975 de Justicia y $\mathrm{Paz}$, las actuaciones frente a los integrantes de estos gremios, grupos empresariales y multinacionales no son competencia de la Sala de Casación Penal, ni de la SJP. Ello ha provocado que las mismas se encuentren todavía en un estado incipiente. Este retraso en las actuaciones, no significa sin embargo que, de acuerdo con los hechos declarados probados por dichas Salas, la "paraeconomía" no haya constituido un pilar esencial en la constitución, desarrollo y consolidación de los grupos paramilitares en Colombia. De hecho, sin los recursos provenientes de la "para-economía" el paramilitarismo en Colombia no hubiera podido alcanzar el grado de expansión que tuvo entre 1999 y 2005.

Un buen ejemplo de esta situación lo describe la SJP en relación con el Frente José Pablo Díaz del Bloque Norte de las ACCU, que operó en la ciudad de Barranquilla y en sus municipios aledaños. Según la SJP, después de un periodo inicial de financiación directa por la Casa Castaño (Carlos y Vicente Castaño fueron los máximos dirigentes de las ACCU), este Frente recurrió a las siguientes fuentes de financiación:

(i) El cobro de porcentajes de participación sobre contratos públicos; así, en diferentes archivos provenientes de los computadores incautados a alias Don Antonio (comandante del Frente José Pablo Díaz), se encontró información sobre las múltiples irregularidades cometidas en la contratación pública en los departamentos del Atlántico, Magdalena y Bolívar por gobernaciones, alcaldías, hospitales, empresas prestadoras de servicios de salud (IPSs, EPSs y ESEs), mataderos y otras empresas de servicios públicos ${ }^{103}$; notables porcentajes del valor de los contratos (relacionados en particular con obras públicas y salud) fueron a parar, según la SJP, a las arcas de este Frente paramilitar, que infiltró completamente las finanzas de centros como el hospital materno infantil del municipio de Soledad ${ }^{104}$;

\footnotetext{
${ }^{103}$ Sala de Justicia y Paz de Bogotá, sentencia de 7 de diciembre de 2011 en el caso contra el comandante del Bloque Norte, Edgar Ignacio Fierro Flores, alias Don Antonio, Radicado 110016000253-200681366, párr.. 13 [en adelante: sentencia de primera instancia en el caso contra alias Don Antonio] ${ }^{104}$ Idem.
} 
(ii) Los aportes a la causa paramilitar requeridos a comerciantes, funcionarios públicos, ganaderos y agricultores (a estos últimos con base en el número de cabezas de ganado que poseían y la extensión de sus fincas); y

(iii) El impuesto a las operaciones del narcotráfico realizadas en el área de influencia del Frente $^{105}$; en particular se impuso un impuesto de gramaje a los estupefacientes y sustancias ilícitas que atravesaban municipios de dicha región como Puerto Colombia, Juan de Acosta, Tubara y Piojón ${ }^{106}$.

Otro ejemplo de la para-economía lo encontramos en el Bloque Elmer Cárdenas de las ACCU, operativo en la región del Urabá de los departamentos de Antioquia, Córdoba y El Chocó. Con respecto al mismo, la SJP de Bogotá ha subrayado que dicho Bloque experimentó desde el año 2000 un fuerte incremento en sus fuentes de financiación debido un mayor acceso a los recursos de los impuestos sobre el narcotráfico, el contrabando y la tala de madera ${ }^{107}$, de manera que los aportes de los ganaderos (incluyendo los impuestos sobre bienes raíces) dejaron de ser su principal fuente de financiación ${ }^{108}$. En particular, la SJP explica como al quitarle el control de los territorios de coca a los grupos de guerrillas, los ingresos del Bloque aumentaron considerablemente ${ }^{109}$, convirtiéndose las actividades relacionadas con el narcotráfico en el factor de mayor importancia en su crecimiento entre 1995 y 2006 (generándole unos ingresos de 70 millones de dólares, equivalente al 80\% de sus ingresos, de los que el $25 \%$ de lo recaudado se enviaba a los hermanos Castaño) ${ }^{110}$.

La SJP ha señalado también que, además del narcotráfico, existían otras fuentes de financiación del Bloque Elmer Cárdenas. Entre ellas destacan los peajes en las carreteras de la región (se cobraban peajes a los conductores de toda clase de vehículos automotores que circulaban por la vía ${ }^{111}$. Se aplicó un impuesto a la entrada y salida de mercancías de la zona de operaciones del Bloque. Se impuso un impuesto al comercio (que se recogía en las cabeceras municipales) y a los establecimientos de apuestas y billares ${ }^{112}$. Se cobró además un gravamen por el gas, que a partir del año 2001 se exigió a todas las empresas que se dedicaban a este negocio en el norte de Antioquia y la región del Urabá (como Cartagás, Intergás, Corona, Gas de Urabá y Batigás) ${ }^{113}$. Finalmente, se grabaron también la madera (siendo Maderas del Daríen el principal "contribuyente") y las actividades de contrabando.

Según la SJP, fueron particularmente importantes las relaciones económicas de este Bloque con las multinacionales, especialmente las exportadoras de Bananos ${ }^{114}$. Desde el año 1997, las ACCU, lideradas por Carlos Castaño, se reunieron con importantes ejecutivos de multinacionales del sector bananero para concertar los mecanismos de seguridad y "normalización o pacificación laboral" en la región $^{115}$. Charles Kaiser, director general de Banadex S.A. y los grupos paramilitares operativos en la región (los Bloques Elmer Cárdenas y Bananero de las ACCU) acordaron un aporte de la multinacional de tres centavos de dólar por cada caja exportada, lo que supuso un ingreso en siete años de un millón setecientos mil dólares ${ }^{116}$. A cambio la industria bananera, según la SJP se benefició de la función de "pacificación" de conflictos laborales y mantenimiento de la seguridad desempeñada por los grupos paramilitares. La SJP dio credibilidad a las declaraciones de alias H.H. (comandante del Bloque Bananeros), en las que afirma que "a medida que fuimos tomando control sobre esta zona,

\footnotetext{
105 Ibid, párrs. 12 y 21.

106 Ibid, párr. 15.

107 Sala de Justicia y Paz de Bogotá, sentencia de primera instancia de 16 de abril de 2012 en el caso contra Orlando Villa Zapata, Radicado 110016000253200883280 , párr. 419 [en adelante: sentencia de primera instancia en el caso contra Orlando Villa Zapata]

108 Ibid, párr. 422.

109 Ibid, párr. 421.

110 Ibid, párr. 441.

111 Ibid, párr. 422

112 Ibid, párr. 425.

113 Idem.

114 Idem.

115 Ibid, párr. 426.

116 Idem.
} 
todos los beneficios laborales se fueron perdiendo, por lo que creo que nuestro accionar sí perjudico al empleado bananero y benefició enormemente a los empresarios"

La SJP ha subrayado también que el Bloque Elmer Cárdenas fue un "agente facilitador" en el desarrollo de proyectos agroindustriales de hoja de palma en el área del Bajo Atrato y Norte del Chocó $^{118}$. Según la SJP, este Bloque jugó un papel sustancial en la consolidación de este tipo de proyectos vinculados a circuitos internacionales en perjuicio de comunidades afro-descendientes que habían poseído históricamente miles de hectáreas de tierra en la región ${ }^{119}$. Parte del territorio abandonado por estas comunidades debido a la violencia ejercida por el Bloque Elmer Cárdenas (3.406 hectáreas según cifras de la Federación Nacional de Cultivadores de Palma de Aceite) fue invadido por empresarios de empresas palmi-cultoras y madereras, con el fin de desarrollar proyectos agroindustriales, y por nuevos pobladores sin vínculo alguno con los territorios históricos de las comunidades del norte del Chocó $^{120}$. Este despojo permitió además la entrada de capitales privados nacionales e internacionales para financiar dichos proyectos ${ }^{121}$.

Un tercer ejemplo lo constituye el Bloque Montes de María, operativo en los departamentos de Sucre y Bolívar, con respecto al cual la SJP de Bogotá ha subrayado lo siguiente:

\begin{abstract}
Se financió este bloque, como lo hicieron los demás que debían obediencia a la casa Castaño, con: 1) tributos concertados a propietarios de fincas a razón de $\$ 10.000$ por hectárea una vez al año, a cambio de seguridad, 2) extorsiones a tenderos, transportadores, estaciones de servicio (aporte consistente en combustible), al comercio en general, empresarios (a manera de ejemplo, Postobón pagaba \$10.000.000 mensuales), contratistas de Ecopetrol y con la empresa de gas encargada de la instalación de las redes de gas domiciliario, contratistas encargados del mantenimiento de la carretera pavimentada, dineros de las transferencias indígenas y en ciudades como Cartagena, cobro a los comerciantes del mercado de bazurto, y 3) lo que realmente se convirtió en la principal fuente de financiación de este bloque fue el narcotráfico, que a partir del 2000 contribuyó con el 75\% del valor de los gastos generados en cada uno de los frentes, según información suministrada por el postulado Cobos Téllez. Una muestra de lo anterior la constituyen las cifras suministradas por quien de manera directa recibía el valor del impuesto de salida de la droga (alias “Diego Vecino”) que dice haber entregado a los 3 frentes de este bloque, de junio de 2004 a julio de 2005 como subsidio para los gastos, la suma tres mil novecientos millones de pesos $(\$ 3.900 .000 .000$.), frente a cuatrocientos veintitrés millones ochocientos mil pesos $(\$ 423.800 .000$.) recibidos de las diferentes alcaldías municipales, y setecientos noventa y tres millones ochocientos ochenta y cuatro mil pesos $(\$ 793.884 .000$.) de otros aportes. Estos dineros los utilizaron en pago de nómina a los integrantes de los 3 frentes, así como informantes, durante ese mismo lapso dos mil novecientos sesenta millones novecientos seis mil pesos (\$2.960.906.000.); cuatrocientos setenta y siete millones cien mil pesos (\$477.100.000.) para pago de autoridades que colaboraron, y mil quinientos treinta y dos millones cientos noventa y tres mil pesos $(\$ 1.532 .193 .000$.) aproximadamente, en logística"122.
\end{abstract}

Si bien, según la SJP, este Bloque no fue creado específicamente con fines de narcotráfico, tuvo una estrecha relación con el mismo, de manera que el narcotráfico constituyó un factor determinante en su financiación, debido al gran valor de los beneficios que se obtenían del mismo ${ }^{123}$. A este respecto, el Grupo de Memoria Histórica de la Comisión Nacional de Reparación y Reconciliación ("Grupo de Memoria Histórica") ha afirmado en el informe sobre la conocida masacre de El Salado:

Los intereses que marcan límites porosos entre los paramilitares y los narcotraficantes vuelven a coincidir y a superponerse. El dispositivo estratégico de la expansión nacional de los paramilitares centrado en crear un corredor que uniera Urabá con Catatumbo y luego consolidar la región Caribe como zona de retaguardia estratégica, de modo coincidencial aparece como funcional a los reacomodos de los intereses de los narcotraficantes, que se

\footnotetext{
117 Ibid, párr. 427.

118 Ibid, párr. 428.

119 Idem.

${ }^{120} \mathrm{Ibid}$, párr. 438.

121 Ibid, párr. 439.

122 Decisión de control de legalidad de la Sala de Conocimiento de Justicia y Paz de Bogotá de 25 de enero de 2010 en el caso contra el comandante paramilitar del Bloque Héroes de los Montes de María, Edgar Cobos Téllez, alias Diego Vecino, y del Frente Canal del Dique, Uber Enrique Bánquez Martínez, alias Juancho Dique, párr. 91 [en adelante: control de legalidad en el caso contra alias Diego Vecino y alias Juancho Dique]. Véase también la sentencia dictada por la misma Sala de Justicia y Paz de Bogotá en este mismo caso el 29 de junio de 2010, párr. 66, nota al pie 31.

123 Control de legalidad en el caso contra alias Diego Vecino y alias Juancho Dique, (supra n 122), párr. 170.
} 
vieron afectados por la política de erradicación de cultivos ilícitos del gobierno Samper con las fumigaciones aéreas en Putumayo, Caquetá y Guaviare realizadas desde el año 1996. Esta política no se modificó en el gobierno Pastrana (1998-2002) sino que se consolidó con el Plan Colombia a partir del año 1999 [...] En ese contexto se inscribe la guerra territorial por la región del Sur de Bolívar, una de las zonas que redobla su importancia estratégica para los actores armados por la expansión de los cultivos ilícitos. El control paramilitar de la región de Sur de Bolívar hizo cambiar la percepción sobre la importancia estratégica de los Montes de María: con el control de la zona de producción y procesamiento de cocaína en el Sur de Bolívar, la cuestión relevante es el acceso hacia la zona de exportación; y en ese momento los Montes de María asumieron una importancia estratégica por su conversión en un corredor que comunica el Sur de Bolívar con el Golfo de Morrosquillo. El desenlace de la guerra en aquel agravó la de los Montes de María, pues escaló la competencia entre los actores armados por un territorio en el cual se concentran intereses vinculados con el negocio del narcotráfico ${ }^{124}$.

El Bloque Catatumbo de las ACCU, operativo junto a la frontera con Venezuela en el departamento del Norte de Santander (municipio de Cúcuta y alrededores), constituye un cuarto ejemplo del fenómeno de la para-economía. Según ha manifestado la SJP, su principal fuente de ingresos era la comercialización de sustancias alucinógenas producidas en su área de operaciones ${ }^{125}$, lo que constituía un "emporio económico" en manos de las ACCU ${ }^{126}$. A tal punto llegó la intervención de este Bloque en el tráfico de estupefacciones que, según la SJP, "participó en todos los eslabones del negocio de la cocaína: los cultivos de plantaciones ubicados en nueve municipios, laboratorios para el procesamiento en Tibú, Aguachica, Sardinata, área metropolitana de Cúcuta, y la comercialización por el Magdalena, la Costa Atlántica y la frontera colombo-venezolana"127.

Pero el narcotráfico no fue la única fuente de financiación del Bloque Catatumbo, sino que, según la SJP, también se recibieron cuotas a cambio de seguridad en muchas de las empresas más representativas de la región, como Termotasajen, Cootranscúcuta, Tejar de Pescadero, Norgas, Gaseosas la Frontera (Postobón), Estación de Servicio San Rafael, Arrocera Gálvez, Carbones la Mirla, Ferretería El Palustre, Inducarga, Colminas y acopio de crudo Cañolimón ${ }^{128}$.

\begin{abstract}
Así mismo, según la Sala, el frente urbano que operaba en la ciudad de Cúcuta, se financió de: cuotas obligatorias que les imponían a centros comerciales como San Andresito o la Alejandría (quienes tenían que aportar un promedio de doscientos mil pesos mensuales por local), los mercados de la sexta, Cenabastos, mercados de barrios, la Plaza las Ferias. También hubo cobro a los conductores de taxis, colectivos piratas y transporte formal. A esto se suma que las empresas de vigilancia tenían que entregar un porcentaje semanal del total recaudado por concepto de celaduría $^{129}$.
\end{abstract}

Un quinto ejemplo de la para-economía lo encontramos en el Bloque Vencedores de Arauca de las ACCU, operativo en el departamento de Arauca, también fronterizo con Venezuela. Con respecto al mismo, la SJP ha subrayado que los gastos de nómina durante el tiempo de operaciones del Bloque ascendieron a aproximadamente siete millones de dólares ${ }^{130}$, de los que hay que sumar 525.000 dólares de gastos de intendencia ${ }^{131}$ y 2.25 millones de dólares de gastos de alimentación ${ }^{132}$. Además, el Bloque destinó un rubro para el pago a informantes de la Policía Nacional, entre los cuales se encontraba el Comandante de la Estación de Policía de Tame, y el Jefe del Puesto Operativo de los servicios de

\footnotetext{
${ }^{124}$ Citado con aprobación por la Sala de Justicia y Paz de Bogotá, en el control de legalidad en el caso contra alias Diego Vecino y alias Juancho Dique, (supra n. 122), párr. 170.

125 Decisión de control de legalidad de 7 de diciembre de 2009 en el caso contra Jorge Iván Laverde Zapata, alias El Iguano, Sala de Conocimiento de Justicia y Paz de Bogotá, caso (radicado) núm. 2006 80281, párr. 4.2.3 [en adelante: control de legalidad en el caso contra El Iguano]

${ }^{126}$ Idem.

127 Idem.

${ }^{128}$ Ibid, párr. 4.3.2.

${ }^{129}$ Idem.

130 Sala de Conocimiento de Justicia y Paz del Tribunal Superior de Justicia de Bogotá, Decisión de Control de Legalidad en el caso contra José Rubén Peña Tobón, alia Lucho, y José Manuel Hernández Calderas, alias Platino, de 12 de agosto de 2011, caso (radicado) núm 2008-83194; 2007-83070, párr. 168 [en adelante: control de legalidad en el caso contra José Rubén Peña Tobón]

131 Ibid, párr. 175.

132 Ibid, párr. 183.
} 
inteligencia (DAS) ${ }^{133}$. En consecuencia, el estimado de gastos de funcionamiento y sostenimiento del Bloque durante sus cinco años de actividad se cifra en 10.5 millones de dólares ${ }^{134}$, lo que significa un gasto mensual de 250.000 dólares $^{135}$.

Según el comandante del Bloque Vencedores de Arauca, Miguel Ángel Mejía Munera, los recursos provenientes de las actividades de narcotráfico que él mismo y su hermano desarrollaban, fueron destinados a la financiación del Bloque para así dotarlo de la logística necesaria y pagar las nóminas de sus miembros ${ }^{136}$. Esta fue la única forma de financiación durante los años 2001 y 2002 , hasta que desde mediados del 2002 el Bloque comenzó a llevar a cabo otras actividades generadoras de ingresos (si bien el narcotráfico continuó siendo su fuente principal de financiación ${ }^{137}$ ). Entre estas nuevas fuentes de ingresos destacaron las exacciones y contribuciones arbitrarias, con respecto a las cuales la SJP ha dado credibilidad a las declaraciones de Miguel Ángel Mejía Munera afirmando que "en todas las guerras ha pasado eso, eso es normal, en todo el mundo se ha extorsionado gente, aunque muchos comandantes abusaron también de eso... por eso yo en el 2003 di la orden de que se colocara un impuesto a las gaseosas, a la cerveza, al ganado y creo que a la gasolina, eso fue manejado por mí, que eso lo hacían todos los bloques del país". ${ }^{138}$

En consecuencia, cono la SJP ha subrayado, a partir del año 2002 el Bloque establece impuestos por: (i) cada finca y cabeza de ganado registrada por los hacendados y finqueros de las zonas rurales ${ }^{139}$; (ii) cada producto vendido por los comerciantes; (iii) cada vez que se utilizaban las vías por los transportadores de mercancías; (iv) cada contrato celebrado con la administración pública del departamento, incluyendo los relativos a la construcción de obras públicas (se cobraba el 10\% de todos los contratos celebrados con la administración pública ${ }^{140}$ ); (v) la venta de combustible y la propiedad de las estaciones de suministro; y (vi) la colaboración con la guerrilla ("sistema de multas a los colaboradores de la guerrilla") ${ }^{141}$. Según la SJP, para facilitar el pago se crearon talonarios con la identificación del Bloque, el nombre de quien efectuaba el pago, el monto, la fecha, la serie que correspondía al número del recibo, y el nombre de quien recibía el pago ${ }^{142}$. Quienes se negaban a pagar las sumas exigidas por el Bloque, eran víctimas de amenazas, intimidaciones, retenciones y atentados contra su persona ${ }^{143}$.

Como tercera fuente de ingreso, el Bloque Vencedores de Arauca comenzó a partir de finales de 2001 una práctica de secuestros extorsivos a miembros de la población, robos de camionetas y motocicletas, y hurtos de materiales, enseres y alimentos en establecimientos de comercio ${ }^{144}$. Además, según la SJP, se estableció una política encaminada al hurto de ganado como fuente de financiación del Bloque. Esta política alcanzó tales proporciones que la producción pecuaria de la zona se vio enormemente afectada, causando un grave deterioro en la economía departamental ${ }^{145}$. Así mismo, la

\footnotetext{
133 Ibid, párr. 184.

134 Ibid, párr. 185

135 Ibid, párr. 188

136 Ibid, párr. 186

137 Las diferencias surgidas entre él y Carlos Castaño durante las negociaciones ante el Alto Comisionado de Paz fueron de naturaleza personal (en particular el asesinato de alias Tolima), y no porque Carlos Castaño condenara el hecho de que fueran narcotraficantes. Véase, control de legalidad en el caso contra José Rubén Peña Tabón (supra n. 130), párr. 188 y 189; y Sala de Conocimiento de Justicia y Paz del Tribunal Superior de Distrito de Bogotá, Decisión de control de legalidad en el caso contra Orlando Villa Zapata (Bloque Vencedores de Arauca) de 12 de diciembre de 2011, radicado 110016000253200883280, párr. 210 [en adelante: control de legalidad en el caso contra Orlando Villa Zapata].

138 Control de Legalidad en el caso contra José Rubén Peña Tobón (supra n. 130), párr. 234.

139 Ibid, párr. 196.

140 A este respecto, en la contabilidad del Bloque aparece el rublo "Contratos Arauca y Multa", con los siguientes tres suburbios: (i) Cobro a contratistas por la celebración de contratos de obras con el Departamento de Arauca; (ii) Cobro a contratistas por la celebración de contratos de obras con el municipio de Hato Corozal; y (iii) "Ingresos por multas a colaboradores de la guerrilla y otros", por valor de Noventa y dos millones quinientos mil (\$92.500.000.) pesos. Véase, control de Legalidad en el caso contra Jose Rubén Peña Tabón (supra n. 130), párrs.218-220. Véase también control de Legalidad en el caso contra Orlando Villa Zapata (supra n. 137), párr. 213.

${ }^{141}$ Control de Legalidad en el caso contra José Rubén Peña Tobón (supra n. 130), párrs. 195 y 212.

142 Ibid, párr. 231.

143 Ibid, párr. 232.

144 Ibid, párr. 195

145 Ibid, párr. 235
} 
SJP subraya la existencia de fuentes de ingresos adicionales, como la "tarjeta navideña" que en el mes de diciembre del 2003 el Bloque hizo circular entre la población de Arauca, y en la que se solicitaba un aporte económico por temporada navideña de dos millones de pesos ${ }^{146}$.

El Bloque Calima de las ACCU, operativo en los departamentos del Tolima, El Cauca, El Valle del Cauca, El Quindío y El Huila, nos proporciona un sexto ejemplo del fenómeno de la "paraeconomía". Con respecto al mismo, la SJP ha afirmado que a principios del año 2000 Carlos Castaño envió a alias H.H. (hasta entonces comandante del Bloque Bananero) para remplazar a alias Román como comandante del Bloque Calima, siendo una de sus primeras acciones las reuniones mantenidas en la finca El Corcobado de Cartago Valle con empresarios y representantes de los gremios económicos de la región, ingenios azucareros, ganaderos y comerciantes que habían sido víctimas de las "vacunas" de la guerrilla, así como con alias Ernesto Báez, alias Don Berna y narcotraficantes que representaban a don Diego, Adolfo Paz y Vicente Castaño. Según la JP; en estas reuniones se acordo apoyar la expansión del Bloque Calima y buscar la colaboración económica de quienes manejaban el poder en el valle del Cauca ${ }^{147}$.

A este respecto, La SJP ha subrayado que Carlos Castaño en persona se reunió ese mismo año con familiares del secuestro masivo de feligreses realizado por el ELN el 30 de Mayo de 1999 en la Iglesia La María del barrio Ciudad Jardín de la ciudad de Cali ${ }^{148}$. Allí se decide enviar a Hernán Gómez y Carlos Spath (este último ex presidente de Avianca) como emisarios ante comerciantes e industriales de la región en búsqueda de apoyo financiero para el Bloque Calima. Según la SJP; la delegación enviada se reunió con empresarios liderados por Edgar Lennis (a su vez ex presidente de Avianca), acordando financiar la acción armada con 250 millones de pesos mensuales ${ }^{149}$. Ahora bien, como la propia SJP señala, una vez que el Bloque Calima entra en Buenaventura, y se crea el frente Pacífico, se suspende este aporte mensual porque el Bloque pasa a financiarse con los ingresos aportados por los narcotraficantes de la región (quienes pagaban un impuesto de cien dólares por kilo de cocaína comercializada) y por el hurto de combustibles ${ }^{150}$.

A este respecto, la SJP ha dado credibilidad a las declaraciones de alias H.H., según las cuales la principal fuente de financiación del Bloque Calima fue el narcotráfico. Así, mientras en sus inicios el Bloque recibió financiación de algunos narcos del Cartel del Norte del Valle ${ }^{151}$, dicho aporte fue temporal y sólo duró hasta que el Bloque Calima desalojó a la guerrilla de su área de operaciones, lo que, según la SJP, le permitió buscar financiación cobrando a todos los narcotraficantes un impuesto de tránsito proporcional a la cantidad de droga que se traficaba ${ }^{152}$. Para controlar que toda la droga que saliera por el puerto de Buenaventura pagara el impuesto, se organizó un grupo de 16 hombres en el alto Calima liderado por alias Chiquito Malo ${ }^{153}$.

En este contexto la SJP ha dado credibilidad a las declaraciones de alias H.H., en las que afirma que "cuando se inicia la etapa de cobro de impuestos en el Valle del Cauca [...] un método que nosotros implementamos en la Costa Atlántica [...] cuando entramos al Valle [...] se hacen reuniones con lancheros y narcotraficantes [...] les notificamos que deben pagar un impuesto so pena de que se decomise la mercancía y/o la muerte de las personas... entonces sí se hicieron reuniones en las que tenían que estar todos los lancheros, se programaban en Calima Daríen [...] quien citaba era el Fino y el Mocho...yo hablaba con la gente...yo hablé personalmente con esos narcos" ${ }^{\text {"154 }}$. Es por ello que para la SJP, el narcotráfico constituyó para el Bloque Calima, al igual que para otros grupos paramilitares en Colombia, un factor determinante en su existencia, lo que no quiere decir que la razón última de su fundación haya sido el tráfico de estupefacientes ${ }^{155}$.

\footnotetext{
146 Ibid, párr. 233.

147 Ibid, párr. 150

148 Ibid, párr. 169

149 Ibid, párr. 152.

150 Idem.

151 Ibid, párr. 476

152 Ibid, párr. 477.

153 Idem.

154 Corte Suprema De Justicia Sala De Casación Pena Proceso No 30097, de 25 de enero 2010.

155 Control de legalidad en el caso contra alias El Tuerto, (supra n. 84), párr.476.
} 
Según la SJP, el Bloque Calima se financió también a través del hurto de hidrocarburos, así como con los aportes suministrados por empresas privadas, comerciantes y ganaderos de la región ${ }^{156}$, quienes pagaban la suma de cinco dólares mensuales por hectárea de tierra ${ }^{157}$. En este sentido, la SJP ha declarado que realizaron aportaciones a la causa paramilitar, entre otras, las empresas lideradas por Edgar Lennis, Hernán Gómez y Carlos Spa, el Ingenio San Carlos, Incopesca, Bahía Cupica de Javier Armitanche, Manaba o Playa Nueva, Timelco, Carnes y Carnes, Galería Pueblo Nuevo, Juancho Transporte, JCM, Gustavo Calle, Milton Mejìa, Restaurante los Balcones, Víctor Olarte en Tulúa, Juan Bautista García Monsalve, Néstor Fabio Álvarez Pereira, Alfonso Luis Cruz, Funeraria San Martín, Graciela Sánchez, Héctor Mondragón Jiménez, Piedad Vélez Rengifo, Carlos Alberto Renterìa Mantilla, Granero JB, García y Hermanos Ltda., Manuel Mosquera, Fernando Piani, Carlos Castro, Bernardo Besna, Andrés Orozco, y la Cooperativa de Ganaderos del Centro del Norte del Valle del Cauca $^{158}$.

Como séptimo y último ejemplo que, por razones de espacio, abordamos en este trabajo, se encuentra la financiación de los numerosos grupos paramilitares operativos en el área metropolitana de Medellín y en el noroccidente antioqueño (entre los que cabe mencionar el Bloque Metro, el Bloque Cacique Nutibara, el Bloque Héroes de Granada y el Bloque Héroes de Tolová). Según ha puesto de manifiesto la SJP, las fuentes de ingresos de estos grupos variaron notablemente. Así, mientras el Bloque Metro, debido a la oposición de su comandante, alias Rodrigo Doblecero, a toda relación entre paramilitarismo y narcotráfico, se financiaba de actividades ilegales como el hurto de combustibles que no estuvieren relacionadas con el narcotráfico (en particular ${ }^{159}$, el resto de Bloques de esta región, al frente de los cuales se encontraba alias Don Berna, tuvo en el narcotráfico su fuente principal de ingresos (lo que acabó generando un conflicto entre grupos paramilitares que provocó el exterminio entre los años 2002 y 2003 de los casi mil quinientos hombres que formaban parte del Bloque Metro en aquel momento ${ }^{160}$.

Es por ello que, como la SPJ ha afirmado que el Bloque Héroes de Granada, creado en 2004 tras la desaparición del Bloque Metro y la desmovilización del Bloque Cacique Nutibara, se financió principalmente del narcotráfico, a lo que unió otras actividades ilícitas como el hurto de hidrocarburos, extorsiones a comerciantes, trasportadores y ganaderos ${ }^{161}$, para lo que contaba con la Oficina de Cobro de Envigado (formada por unas 70 personas) que tenía a su servicio numerosas bandas y parches que rondaban los 1.160 miembros en la zona Metropolitana de Medellín ${ }^{162}$.

En conclusión, como la SJP ha subrayado, el fenómeno de la para-economía tuvo un profundo impacto en la economía de los distintos departamentos del país, debido a sus numerosas externalidades negativas, las cuales han sido descritas en los siguientes términos por la propia SJP en relación con el Departamento de Arauca:

[...] afectó varios aspectos, a saber: el establecimiento de un sistema paralelo de tributación por parte de los actores armados; la restricción de la circulación de mercancías y mano de obra; la reducción masiva del ingreso provocada por una desactivación económica crítica, derivada del desplazamiento forzado interno; efecto negativo sobre el ingreso de la actividad agropecuaria, adicional a la restricción del paso de insumos agropecuarios, gasolina y cemento; restricción del paso de mercancías hacia el sector rural, incluidos los bienes de canasta familiar y las drogas, bajo la hipótesis de que los pequeños productores son cómplices o colaboradores de la guerrilla a la que le llevan provisiones o medicinas; y finalmente, los altos costos de la provisión de bienes públicos en el área rural por las fallas de conectividad derivada de la presencia de grupos armados ilegales que provoca un efecto circular de reducción de ofertas de bienes públicos (construcción de vías, prestación de servicios de asistencia técnica para la

\footnotetext{
156 Ibid, párr.184.

157 Ibid, párr.189.

158 Ibid, párr.190.

159 Tribunal Superior de Bogotá, Sala de Conocimiento de Justicia y Paz. Decisión de legalidad de cargos en el caso contra

Giraldo Paniagua, alias Pitufo, de 6 de diciembre de 2011, M.P: Uldi Teresa Jiménez López. Radicado:

110016000253200682222 , párr. 20 [en adelante: control de legalidad en el caso contra Edison Giraldo Paniagua]

160 Idem

161 Ibid, párr. 30.

162 Ibid, párrs. 165 y 171.
} 
producción, etc.), el riesgo que corren los ejecutores de estas actividades incrementa el costo de prestación a este nivel que no son pagables por el gobierno local ${ }^{163}$.

\section{El apoyo estratégico y logístico a los grupos paramilitares de sectores de las Fuerzas Armadas, Policía Nacional, servicios de inteligencia (DAS) y las administraciones públicas}

La Sala de Casación Penal y la SJP han puesto también de relieve la importancia del apoyo estratégico y logístico de los miembros de las Fuerzas Armadas, Policía Nacional, servicios de inteligencia (DAS) y administraciones públicas (dentro de estas últimas, en particular, las áreas de educación, sanidad y justicia) en la expansión y consolidación de los grupos paramilitares en Colombia.

En relación con las Fuerzas Armadas y la Policía Nacional, y sin ánimo de ser exhaustivos $^{164}$, baste a los efectos del presente trabajo afirmar que dichas Salas han identificado las siguientes modalidades de cooperación de ciertos sectores de estas instituciones con los grupos paramilitares:

(i) Una parte importante de los mandos medios de los grupos paramilitares (e incluso algunos comandantes de alto rango como Rodrigo Doblecero) - incluyendo a quienes dirigían las escuelas de entrenamiento paramilitar, y quienes se encontraban a cargo de la adquisición del material de intendencia y diseño de operativos de cierta envergadura - fueron ex miembros de las Fuerzas Armadas y la Policía Nacional;

(ii) La asistencia en la obtención de armamento, municiones y otros materiales de intendencia;

(iii) El apoyo a nivel estratégico y operacional frente a la expansión de los grupos paramilitares; $y$

(iv) La formación de los nuevos reclutas de los grupos paramilitares ${ }^{165}$;

En cuanto a la colaboración recibida por los servicios de inteligencia del Estado (en particular, por el Departamento Administrativo de Seguridad, DAS), la SJP ha afirmado que el propio subdirector general de dicha institución, José Miguel Narváez, actuó como instructor en las escuelas de formación paramilitares ${ }^{166}$. Además, la propia SJP ha puesto de manifiesto la estrecha relación de las ACCU con el ex director de informática del DAS, Rafael García Torres ${ }^{167}$. Así mismo, la SJP ha subrayado repetidamente, la colaboración con los grupos paramilitares de aquellos miembros del DAS desplegados en las áreas de actuación de dichos grupos. Sin ir más lejos, este es el caso, por ejemplo, del subdirector de la seccional del DAS en Cúcuta, Jorge Enrique Díaz y Viterbo, y del investigador del DAS en esa misma localidad, Efraín Morales ${ }^{168}$. Todas estas decisiones parecen haber sido un factor relevante en la decisión adoptada el año pasado por el actual presidente de la República, Juan Manuel Santos, de disolver el DAS.

En relación con el apoyo recibido por autoridades civiles y miembros de las administraciones públicas (en particular, en las áreas de educación, sanidad y justicia), baste mencionar algunos de los numerosos ejemplos dados por la SJP. Así, la SJP ha afirmado que el Bloque Norte de las ACCU contó con una estructura política, financiera y armada, que le permitió convertirse en una macroestructura criminal, que se valió de la colaboración por acción u omisión de todo tipo de autoridades y

\footnotetext{
163 Control de legalidad en el caso contra alias El Iguano (supra n. 125), párr. 2.4.2.

164 Para un análisis más exhaustivo, véase H. Olásolo Alonso, Autoría y participación en Derecho penal internacional, Temis, Universidad Sergio Arboleda \&Instituto Iberoamericano de la Haya para la Paz, los Derechos Humanos y la Justicia Internacional (IIH), Bogotá, 2012 (en prensa).

165 Véase H. Olásolo, “Autoría y Participación en el Derecho penal internacional”, Editorial Temis, Univesidad Sergio Arboleda \& Instituto Ibero-americano de la Haya (IIH), 2012 (en prensa).

166 Control de legalidad en el caso contra alias El Iguano (supra n. 125), párr. 4.3.4.

167 Control de legalidad en el caso contra alias El Alemán (supra n. 91), párr. 10.

168 Idem.
} 
funcionarios en sus procesos de consolidación y expansión ${ }^{169}$. En particular, la SJP ha puesto de relieve que el Bloque Norte llegó a infiltrarse en importantes sectores de la administración pública local y regional, además de contar con el apoyo de un buen número de parlamentarios nacionales y gobernadores de la costa Caribe ${ }^{170}$.

Según la SJP, una situación parecía se presentó en el caso del Bloque Catatumbo (y de su Frente Fronteras), que, en opinión de la SJP, se beneficiaron de la colaboración de un nutrido grupo de autoridades civiles y políticas y servidores públicos, entre los que se encontraban la directora seccional de fiscalías de Cúcuta (Ana María Flórez) y su asistente (Magali Yaneth Moreno Vera), el alcalde de Cúcuta (Ramiro Suárez Corso), el alcalde de Puerto Santander (Ramón Elías Vergel Lázaro), el alcalde de Puerto Santander (José Edmundo Mogollón), el alcalde de Salazar de las Palmas (Luís Fernando Valero Escalante), el concejal de Cúcuta (Ramón Eder Mendoza Vargas), el concejal de Patios (Carlos Rangel), y el director de la cárcel modelo de Cúcuta (Hernán Darío Mejía Petrocelli) ${ }^{171}$.

Del mismo modo, la SJP ha subrayado que el Bloque Calima, a través de Carlos Efrén Guevara Cano alias "Fernando el político", recibió el apoyo de autoridades civiles de la región como el gobernador del Cauca, Juan José Chaux, el alcalde de San Pedro (Cerlimo Bedoya), el alcalde de Puerto Tejada (Fernando Santa), el alcalde de Santander de Quilichao, la alcaldesa de Yumbo entre 2002 y 2003 , y el alcalde de Buenventura, Félix Ocoro ${ }^{172}$.

Por último, hay que subrayar que, según la SJP, los grupos paramilitares, además de desviar una parte muy importante de los recursos públicos asignados a educación y sanidad en muchos de los departamentos del país, trataron también de controlar las universidades de las regiones en las que operaron. En este sentido, la SJP ha subrayado que el Bloque Héroes de los Montes de María incursionó en las universidades (particularmente en las públicas) por orden de Salvatore Mancuso, pues existía información de que activistas de la subversión se encontraban allí infiltrados. Con ello, además de cortar las redes de milicianos en las universidades, se pretendía tener acceso al presupuesto de las universidades, que, en casos como el de la Universidad de Córdoba, era similar al de la propia Gobernación. Para ello, según la SJP, se ordenó el asesinato de rectores y docentes vinculados a la universidad. Si bien, la propia SJP subraya que no se pudo reproducir en todas las universidades en las que se intentó (véase por ejemplo el caso de la Universidad de Sucre) el mismo grado de control que las ACCU llegaron a tener en la Universidad de Córdoba ${ }^{173}$.

\section{Conclusiones el examen preliminar de la situación en Colombia y el actuar de los órganos jurisdiccionales nacionales}

$\mathrm{Al}$ analizar en detalle el contenido y alcance de las resoluciones de la Sala de Casación Penal y la SJP sobre la formación, consolidación y expansión de los grupos paramilitares en Colombia, y el entramado político, económico, militar y administrativo que facilitó este proceso, se observa como la profundidad con la que se analizan fenómenos como el de la "para-política" o la "para-economía" es mayor que la que se puede encontrar en el análisis de fenómenos similares por tribunales penales internacionales en relación con los actores armados que intervinieron en los conflictos de la ex Yugoslavia, Sierra Leona, Ruanda, República Democrática del Congo, República Centro-Africana o Sudán (Darfur), por poner sólo algunos ejemplos. Esta situación no es sorprendente si tenemos en cuenta que, junto al alto nivel de independencia mostrado por los magistrados de la Sala de Casación Penal y la SJP frente a los poderes ejecutivo y legislativo, se han dado también los siguientes factores:

(i) El minucioso entendimiento que de la situación colombiana poseen los magistrados, letrados y analistas responsables de las decisiones de la Sala de Casación Penal y de la SJP;

\footnotetext{
169 Ibid, párr. 3.

170 Ibid, párr. 10.

${ }^{171}$ Control de legalidad en el caso contra alias El Iguano (supra n. 125), párr. 4.3.4.

172 Control de legalidad en el caso contra alias El Tuerto (supra n. 84), párr.191.

173 Idem.
} 
(ii) La proximidad a la escena de los delitos y el acceso a los elementos de prueba (en particular, las confesiones de los comandantes paramilitares desmovilizados sobre la manera en la que se crearon, consolidaron y expandieron las estructuras que ellos mismos dirigían); y

(iii) El alto nivel de capacitación que han recibido magistrados, letrados y analistas por parte de formadores con amplia experiencia profesional en investigaciones y enjuiciamientos ante tribunales penales internacionales.

En estas circunstancias, se puede entender el por qué la Fiscalía de la CPI, en lugar de decidir la apertura de la investigación en Colombia, se ha decantado hasta el momento por promover el desarrollo de las actuaciones nacionales, a pesar de que las mismas han llevado tiempo en cristalizar y se han desarrollado desde su inicio con notables dificultades, como lo muestra el hecho de que la Comisión Interamericana de Derechos Humanos haya tenido que adoptar medidas de protección a favor de la mayoría de los magistrados de la Sala de Casación Penal debido a las amenazas de muerte recibidas como consecuencia de sus actuaciones judiciales.

Con su forma de proceder en la situación en Colombia, la Fiscalía de la Corte ha respondido tanto desde la perspectiva de la extensión temporal de sus exámenes preliminares, como del contenido del análisis de admisibilidad que ha de realizarse antes de solicitar la autorización para iniciar una investigación, a la siguiente pregunta:

\begin{abstract}
A pesar de tener indicios de la independencia y voluntad de los órganos jurisdiccionales nacionales competentes de llevar a cabo actuaciones procesales dirigidas a dilucidar minuciosamente la composición, operaciones y apoyo recibido por los actores armados que intervinieron en la comisión de delitos de la competencia de la CPI, ¿debería abrirse la investigación cuando se percibe la existencia de dificultades notables en el desarrollo de tales actuaciones? O por el contrario, ¿consiste la función de la Fiscalía de la CPI en mantener abierto el examen preliminar, para apoyar indirectamente el debilitamiento de aquellos elementos que obstaculizan el avance de las actuaciones judiciales nacionales, y respaldar a aquellos otros actores nacionales, que frecuentemente a riesgo de sus vidas, deciden seguir adelante con la investigación y enjuiciamiento de los principales responsables de dichos delios??
\end{abstract}

Al decantarse en el caso de Colombia por la segunda opción, la Fiscalía de la CPI, no sólo ha adoptado una posición dirigida al fortalecimiento del estado de derecho y las instituciones judiciales colombianas, sino que ha evitado caer en una interpretación del principio de complementariedad que tiene el riesgo de convertir a dicho principio en una bonita idea que no puede ser realmente aplicada en la práctica, puesto que en jurisdicciones sometidas a procesos de violencia masiva de carácter sistemático o generalizado durante periodos prolongados de tiempo: (i) o bien se produce una ruptura abrupta con el "antiguo régimen" (lo que normalmente ocurre de manera violenta y con intervención directa o indirecta de terceros estados); (ii) o bien las autoridades judiciales nacionales se enfrentan con el problema de que los autores de los delitos, o sus cómplices, se encuentran todavía en situaciones de poder, desde donde tratan de obstaculizar las investigaciones y enjuiciamientos que se pretenden desarrollar a nivel nacional.

En consecuencia, si la Fiscalía hubiera adoptado como criterio de política criminal el comienzo de una investigación cuando se presentan dificultades serias en el actuar de los órganos jurisdiccionales nacionales, el principio de complementariedad sería privado de eficacia en este último escenario.

En el caso colombiano estas dificultades se centran principalmente en cuatro aspectos fundamentales:

(i) La lentitud con la que se han tramitado los primeros procesos a nivel nacional (en particular, las SJP han necesitado tres años y medio, para dictar la primera sentencia condenatoria de un comandante paramilitar el 29 de junio de 2010):

(ii) La imposibilidad de poner fin de un día para otro a modelos de conducta que han operado durante décadas; 
(iii) La extradición en 2008 de varios comandantes paramilitares a los EEUU para enfrentar cargos de narcotráfico; y

(iv) La falta de difusión a nivel nacional, regional y local de las decisiones de la Sala de Casación Penal y de la SJP en lo que se refiere al extenso entramado político, económico, militar y administrativo que permitió la creación, consolidación y expansión de los grupos paramilitares en Colombia.

Con respecto al primer factor, la lentitud en las actuaciones ha puesto de manifiesto las dificultades que la SJP estaba enfrentando en la contextualización de las distintas estructuras paramilitares y del complejo entramado que las apoyó. Estas dificultades han incluido, entre otros, los siguientes elementos:

(i) La necesidad de recibir formación sobre la construcción de este tipo de contextos complejos que, siendo habituales en tribunales penales internacionales, no se habían construido judicialmente con anterioridad a nivel nacional;

(ii) La importante resistencia encontrada para que los intervinientes en los procesos de justicia y paz aportaran al proceso la prueba necesaria para poder contextualizar el operar de los grupos paramilitares (razón por la cual la SJP emitió el auto de 23 de agosto de 2010 que recogió el Protocolo para la Presentación de Medios de Prueba);

(iii) Los problemas que planteaba una legislación nacional que, si bien introdujo en la Ley 599 de 2000 los delitos de genocidio y las infracciones graves al Derecho internacional humanitario, no recoge la categoría de los delitos de lesa humanidad (que es aquel en el que verdaderamente se subsume el accionar criminal de los grupos paramilitares).

De carácter más estructural es la cuestión relativa al tiempo necesario para acabar con formas de comportamiento que han regido el país durante décadas. En este sentido, conviene subrayar el hecho de que cerca de la mitad de los miembros y mandos medios de los grupos paramilitares (incluyendo alguno de sus más altos dirigentes, como Vicente Castaño), decidieron no desmovilizarse en el marco del proceso de justicia y paz, y terminaron formando las llamadas "Bandas Criminales" (BACRIM). Ahora bien, este fenómeno es necesario analizarlo en el contexto de una situación en la que durante décadas se ha recurrido a la violencia organizada para salvaguardar el poder político y económico, y en la que una gran parte de la financiación de los grupos armados a través de los que se ha ejercido esta violencia organizada se ha financiado con ingresos provenientes del narcotráfico, el contrabando o la explotación ilegal de recursos naturales, actividades que todavía se siguen desarrollando en el país. En consecuencia, no parece razonable esperar que cambie de un día para otro la cultura de quienes han venido operando de esta manera en una parte muy importante de los departamentos del país, así como de los miles de personas cuya principal profesión ha sido el sicariato y la extorsión dentro de grupos paramilitares, guerrillas, o estructuras de crimen organizado. Si bien el objetivo ha de ser la reducción progresiva de los niveles de violencia, es probablemente necesario que una nueva generación que no haya "absorbido" desde su juventud esta forma de actuar llegue al poder político, económico, militar y administrativo, para que se produzca una verdadera transición hacia un modelo en el que el medio para preservar el poder político y económico deje de ser el recurso a la violencia.

Íntimamente relacionado con los modelos de conducta asumidos durante décadas de violencia masiva en Colombia, es el alto grado de desconfianza de las víctimas y de sus asociaciones hacia las medidas de investigación, enjuiciamiento y reparación promovidas desde Ejecutivos y Legislativos dirigidos por grupos políticos que en el mejor de los casos son percibidos como "no afines", y en el peor como alineados con los victimarios. El diálogo y la búsqueda de consensos son un elemento fundamental para generar confianza y salir de una situación inicial de enfrentamiento. Sin embargo, el proceso de tramitación de la Ley 975 de Justicia y Paz respondió hasta su aprobación en la Cámara de Representantes y el Senado a un proyecto del Ejecutivo de aquel momento, apoyado por su mayoría 
parlamentaria, que poco tuvo en consideración lo que la oposición tuvo que decir al respecto. Fue por ello, que a pesar de las profundas modificaciones introducidas en la Ley por la sentencia C-370 del Tribunal Constitucional, las víctimas de los grupos paramilitares y las asociaciones que las representan rechazaron inicialmente de manera frontal la misma y por lo tanto decidieron no participar en las actuaciones judiciales que se pusieron en marcha a partir de 2007. Solamente con el paso de los años, se han incorporado paulatinamente al proceso a los efectos de participar en las audiencias con su testimonio y versión sobre los hechos confesados por los paramilitares desmovilizados.

Los modelos de comportamiento no sólo afectan a víctimas y victimarios, sino que también juegan un papel muy importante en los operadores jurídicos con competencia para conducir las investigaciones y enjuiciamientos. En particular destaca la situación de aquellos operadores jurídicos que actúan fuera de las grandes ciudades en las zonas rurales del país, y que debido a la falta de estado, o a su debilidad frente a los grupos armados organizados operativos en dichas regiones, y por lo general en aras de preservar su seguridad (numerosos son los casos de asesinatos de fiscales, defensores públicos y jueces que han seguido adelante con sus actuaciones a pesar de las amenazas recibidas), han decidido tradicionalmente hacer "la vista gorda", archivar las actuaciones o incluso colaborar activamente con los grupos armados con mayor presencia en su jurisdicción (sólo así se puede explicar que a pesar de los más de dos cientos mil asesinatos y desapariciones forzadas cometidas en Colombia entre 1991 y 2005, apenas se hayan tramitado unas decenas de expedientes).

La creación de las condiciones materiales necesarias para preservar en los distintos departamentos del país la seguridad de jueces, fiscales, procuradores, defensores públicos, y representantes de víctimas, condición esencial para que puedan operar con independencia e imparcialidad, necesita de un periodo de tiempo razonable, y de la adopción de medidas que no necesariamente tengan una naturaleza penal, como la puesta en marcha de programas de desvinculación administrativa de aquellos miembros de las Fuerzas Armadas, la Policía Nacional, los servicios de inteligencia y otras administraciones públicas, que tal y como afirman las sentencias de la Sala de Casación Penal y de la SJP, han promocionado, financiado o asistido a los grupos paramilitares en la realización de actos de violencia sistemática contra la población civil.

Ahora bien, la adopción de medidas legislativas como las planteadas en los últimos meses, que prevén una extensión del ya existente fuero militar o que atribuyen al Jefe del Estado la potestad para determinar discrecionalmente quién puede ser excluido de un proceso penal, no parecen ir en la línea del fortalecimiento de esas condiciones materiales, y constituyen un retroceso notable en el camino que, a pesar de las dificultades, se ha comenzado a caminar, lo que, sin duda, no puede ni pasar desapercibida, ni dejar indiferente, a quienes con su examen preliminar de la situación en Colombia pretenden incentivar a las autoridades nacionales para que sigan caminando por el camino iniciado con las investigaciones y enjuiciamientos de la Sala de Casación Penal y la SJP.

Por ello, es difícil de entender la persistencia en el impulso que desde el actual Ejecutivo se quiere dar a la extensión del fuero militar a la luz de la tendencia internacional, avalada por las exigencias de la jurisprudencia de los tribunales regionales de derechos humanos, hacia una progresiva limitación del alcance de una jurisdicción excepcional como la jurisdicción militar (y más aun en un momento en el que las sentencias de la Sala de Casación Penal y de SJP señalan la presunta responsabilidad penal por vinculación con grupos paramilitares de un número no desdeñable de mandos altos e intermedios de las fuerzas armadas). Así mismo, también causa preocupación, que a través del llamado "Marco Jurídico para la Paz, se quiera atribuir al Jefe de Estado la competencia para determinar quienes no han de ser objeto de persecución penal en un momento en el que después de varios años las sentencias de la Sala de Casación Penal y la SJP están poniendo de manifiesto el extenso entramado político, económico, militar y administrativo que facilitó la creación, consolidación y desarrollo de los grupos paramilitares. Además, no puede pasar desapercibido, que según la normativa propuesta, la exclusión del proceso penal no es adoptada por una comisión dotada de las necesarias garantías de independencia e imparcialidad en su selección y actuar, ni conlleva contraprestación (como la contribución a la determinación de la verdad de los hechos y a la 
identificación de las personas que dentro o fuera del propio grupo o institución colaboraron de manera similar) o consecuencia alguna para sus beneficiarios (como la entrega de bienes para la reparación de las víctimas o la desvinculación administrativa de la institución a la que pertenezcan).

La tercera dificultad seria enfrentada por las investigaciones y enjuiciamientos desarrollados en Colombia con respecto a los grupos paramilitares ha sido la extradición en 2008 de un buen número de comandantes paramilitares, lo que constituyó para algunos la estocada definitiva a un proceso de justicia y paz que no acababa de arrancar. Para quienes defienden esta posición, la extradiciones evitaban que los comandantes desmovilizados de más alto rango pudieran ser enjuiciados en Colombia por delitos de lesa humanidad y crímenes de guerra, impidiendo así que pudieran seguir contribuyendo con sus declaraciones al esclarecimiento de la verdad (esperándose además que estos comandantes, dada su posición de dirigencia, tuvieran un conocimiento más cercano de los fuertes vínculos de los grupos paramilitares que comandaban con autoridades de carácter político, militar y administrativo a nivel nacional, y con grupos económicos con presencia en el conjunto del país).

Ahora bien, si bien la gravedad de estas extradiciones no puede ser soslayada, lo cierto es que el efecto inmediato que las mismas tuvieron en muchos de los subordinados directos de los comandantes extraditados fue la decisión de completar sus declaraciones previas al entender que la extradición de sus superiores constituía una "traición" a lo acordado con el Ejecutivo durante el proceso de negociación de la Ley de Justicia y Paz. Un buen ejemplo de esta situación es el caso de alias El Iguano, comandante del Frente Fronteras del Bloque Catatumbo, que en las nuevas declaraciones realizadas tras la extradición de su superior (Salvatore Mancuso, comandante del Bloque Norte de las ACCU) desveló el entramado político, económico, militar y administrativo que favoreció la formación, consolidación y expansión del Bloque Catatumbo en el departamento del Norte de Santander.

El cuarto factor que ha dificultado las investigaciones y enjuiciamientos desarrollados en Colombia es la falta de difusión a nivel nacional, regional y local de las decisiones de la Sala de Casación Penal y de la SJP en lo que se refiere al extenso entramado político, económico, militar y administrativo que permitió la creación, consolidación y expansión de los grupos paramilitares en Colombia. A este respecto conviene subrayar que entre las condiciones materiales necesarias para que los procesos penales por delitos de lesa humanidad y crímenes de guerra, así como las actuaciones relativas a las reparaciones a las víctimas, puedan avanzar adecuadamente a nivel nacional dentro de un espacio de tiempo razonable, emerge como un elemento fundamental la adecuada difusión a nivel nacional, regional y local, de los contextos en los que operaron los grupos que cometieron dichos delitos y que a día de hoy han sido minuciosamente recogidos en varias de las sentencias emitidas en los últimos dos años por la SJP.

Sacar a la luz pública los distintos factores que rodearon durante decenas de años situaciones de violencia sistemática, e informar adecuadamente sobre los mismos a la población que sufrió dicha violencia, es un paso fundamental para alcanzar estos objetivos, y por tanto debería ser tenida en consideración por la CPI al aplicar el principio de complementariedad. En el caso de Colombia, esto significa analizar: (i) los mecanismos y el grado de difusión que tienen las decisiones dictadas por la Sala de Casación Penal y la SJP; (ii) los esfuerzos para se recoja en la prensa escrita, la radio y la televisión, los hechos considerados probados en las sentencias firmes de aquellas Salas (así como de otros órganos jurisdiccionales colombianos que adelantan procesos por delitos de lesa humanidad o crímenes de guerra), de manera que la sociedad colombiana pueda tener acceso y conocer lo que realmente ocurrió, las razones por las que ocurrió y los dirigentes que promovieron y facilitaron dicho acontecer.

A este respecto conviene señalar que, a pesar de las actuaciones nacionales arriba descritas, el nivel de exposición pública en Colombia de las mismas es muy limitado, habiéndose realizado únicamente un esfuerzo en este sentido en relación con la primera sentencia dictada por la SJP el 29 de junio de 2010 en el caso contra los comandantes paramilitares del Bloque Montes María, alias Diego Vecino y alias Juancho Dique. En esta misma dinámica, se sitúa la ausencia en las universidades colombianas de cursos en lo que se aborde la aplicación interna del derecho penal internacional en 
Colombia, lo que llama particularmente la atención a la luz de los frecuentes seminarios sobre el funcionamiento y actuación de la Corte Penal Internacional organizados en Colombia.-Es por ello que cabe felicitarse por la decisión de la Universidad Santo Tomás de Aquino de abrir su propuesta curricular a esta disciplina, uniéndose de esta manera a la Escuela Superior de Guerra y a la Clínica Jurídica de Derecho Penal Internacional y Derecho Internacional Humanitario de la Facultad de Jurisprudencia de Nuestra Señora del Rosario, donde desde el año pasado se viene impartiendo esta materia de forma regular.

A pesar de la grandes dificultades enfrentadas por las actuaciones nacionales en Colombia, muchas de las cuales todavía se mantienen, lo cierto es que la posición de la Fiscalía de la CPI de mantener abierto el examen preliminar para a través del mismo promover el debilitamiento de aquellos elementos que obstaculizan el avance de las actuaciones judiciales nacionales, y respaldar a aquellos otros actores que, a pesar de las dificultades, están investigando y enjuiciando paulatinamente en Colombia a los principales responsables por la violencia masiva desplegada por el paramilitarismo contra la población civil, está comenzando a dar fruto $\mathrm{El}$ análisis arriba presentado de la jurisprudencia de la Sala de Casación Penal y la SJP permite afirmar que los esfuerzos genuinos de estos órganos jurisdiccionales, se están viendo finalmente reflejados en las sentencias dictadas por los mismos a partir de finales de 2008 y 2010 respectivamente.

Si bien estas sentencias no son sino el principio de las que tendrán necesariamente que seguirles a la vista de los contextos que describen, de las miles de copias compulsadas en relación con dichos contextos, de los cientos de procesos que ya a día de hoy están comenzando a iniciarse fuera del ámbito de las actuaciones de la Sala de Casación Penal y de la SJP, y de las próximas actuaciones ante la SJP en relación con los desmovilizados de las guerrillas de las FARC y del ELN, lo cierto es que difícilmente se hubiera podido llegar a esta situación sin que la Fiscalía de la CPI hubiera mantenido su examen preliminar sobre Colombia ante la CPI, y sin que los órganos jurisdiccionales colombianos hubieran mostrado el grado de apertura a la recepción del derecho penal internacional como lo muestra: (i) la intensa formación solicitada y recibida a este respecto; (ii) la implementación del Protocolo para la Presentación de Medios de Prueba; (iii) la introducción por la Sala de Casación Penal de la categoría de los delitos de lesa humanidad a través de la aplicación del Bloque de Constitucionalidad; y (iv) la aceptación de formas de autoría y participación (como la autoría mediata a través de estructuras organizadas de poder, la coautoría mediata e incluso la responsabilidad del superior) que son de aplicación habitual ante los tribunales penales internacionales pero que no habían sido previamente aplicadas a nivel nacional en Colombia ${ }^{174}$.

\section{Conclusión}

La estrategia que está aplicando la Fiscalía de la CPI en el caso de Colombia se debe en gran medida a ciertas características singulares de esta situación como: (i) la independencia y operatividad de ciertos órganos jurisdiccionales nacionales colombianos (en particular las Salas de Casación Penal y la SJP); (ii) la voluntad de estos órganos jurisdiccionales de proceder con las investigaciones y enjuiciamiento por delitos de lesa humanidad y crímenes de guerra incluso si ello supone un enfrentamiento con sectores políticos, económicos, militares o administrativos cercanos al gobierno de turno; (iii) el alto nivel de acceso a los elementos de prueba debido a las declaraciones realizadas por los propios comandantes paramilitares desmovilizados; y (iv) la apertura a recibir cursos de formación de profesionales con una dilatada experiencia profesional en el desarrollo de investigaciones y enjuiciamientos ante tribunales penales internacionales.

174 H. Olásolo Alonso, Autoría y participación en Derecho penal internacional, Temis, Universidad Sergio Arboleda \&Instituto Iberoamericano de la Haya para la Paz, los Derechos Humanos y la Justicia Internacional (IIH), Bogotá, 2012 (en prensa). 
No creemos, sin embargo, que esta misma estrategia que pueda ser aplicada con éxito a otras situaciones con características muy diferentes a la situación en Colombia porque (i) no existe un apartado judicial operativo que sea capaz de mantener su independencia frente a los poderes Ejecutivo y Legislativo; (ii) los órganos jurisdiccionales nacionales no tienen la voluntad de proceder a la investigación y enjuiciamiento de los principales actores de los grupo armados implicados en la comisión de delitos internacionales; (iii) no se tiene acceso a los elementos de prueba porque, a falta de confesiones de quienes cometieron dichos delitos, o colaboraron en su comisión, no se permite el acceso a aquellos archivos oficiales donde puedan encontrarse documentados; o (iv) debido a falta de apertura a recibir una adecuada formación en las investigación y enjuiciamiento de delitos como el genocidio, la lesa humanidad o los crímenes de guerra (especialmente sus elementos contextuales), se fraccionan los casos sin analizar los patrones de conducta y el contexto político, económico, militar o administrativo en el que se cometen los delitos.

Esto ocurrió precisamente en las situaciones en Libia y Darfur, donde al iniciarse el examen preliminar se constató la falta de independencia de su aparato judicial, y la actitud desafiante de sus máximos dirigentes (Muammar Gaddafi y Omar al Bashir) hacia el mandato, función y legitimidad de la CPI.

Una situación intermedia fue la ocurrida en la República de Kenia, en el que después de promover las actuaciones nacionales durante casi dos años, la Fiscalía de la CPI llegó a la conclusión de la falta de voluntad del gobierno y del parlamento de dotarse de las herramientas necesarias para llevar a cabo una adecuada investigación y enjuiciamiento de los principales responsables de la violencia acaecida tras las elecciones de diciembre de 2007.

Por ello, las diferentes estrategias adoptadas por la Fiscalía de la CPI en cada una de estas situaciones, lejos de ser arbitrarias como algunos se esfuerzan en presentar, se encuentran justificadas por los diferentes factores que caracterizaban cada una de ellas (si bien ha de subrayarse, que el informe presentado por la Fiscalía el 13 de diciembre de 2011, no tiene en relación con el examen preliminar de la situación en Colombia la profundidad que hubiera sido deseable para el primer informe sobre el estado de dicho examen preliminar desde su inicio en 2005.

Este hecho no afecta, sin embargo, a la conclusión de que a día de hoy, después de los diez primeros años en el actuar de la CPI, se puede afirmar:

(i) La importante función que la CPI ha comenzado a jugar en al marco de la Comunidad Internacional (fruto de su mandato con respecto a situaciones en las que se han producido delitos de lesa humanidad, crímenes de guerra o genocidio);

(ii) La constatación de que cada situación bajo análisis requiere una estrategia de actuación diferente debido a las particulares circunstancias que la rodean; y

(iii) La relevancia de la fase de examen preliminar para que a través de la misma, y siempre y cuando las circunstancias de la situación bajo análisis así lo permitan, se promueva el fortalecimiento del estado de derecho y de los órganos jurisdiccionales nacionales a los efectos de que puedan ser estos últimos los que desarrollen las investigaciones y enjuiciamientos de los delitos de la competencia de la CPI cometido en su territorio o por sus nacionales. 